OPEN ACCESS

Edited by:

Yong Zhao,

Institute of Zoology (CAS), China

Reviewed by:

Nathan Karin,

Technion-Israel Institute of

Technology, Israel

Huanfa Yi,

Jilin University, China

*Correspondence:

Kiran Singh

singhk4@rediffmail.com; skiran@bhu.ac.in

Specialty section:

This article was submitted to Immunological Tolerance and

Regulation,

a section of the journal

Frontiers in Immunology

Received: 31 May 2018 Accepted: 12 November 2018

Published: 28 November 2018

Citation: Budhwar S, Verma P, Verma R, Rai S and Singh $K$ (2018) The Yin and Yang of Myeloid Derived Suppressor Cells.

Front. Immunol. 9:2776.

doi: 10.3389/fimmu.2018.02776

\section{The Yin and Yang of Myeloid Derived Suppressor Cells}

\author{
Snehil Budhwar ${ }^{1}$, Priyanka Verma ${ }^{1}$, Rachna Verma ${ }^{1}$, Sangeeta Rai ${ }^{2}$ and Kiran Singh ${ }^{1 *}$ \\ ${ }^{1}$ Department of Molecular and Human Genetics, Institute of Science, Banaras Hindu University, Varanasi, India, ${ }^{2}$ Department \\ of Obstetrics and Gynecology, Institute of Medical Sciences, Banaras Hindu University, Varanasi, India
}

In recent years, most of our knowledge about myeloid derived suppressor cells (MDSCs) has come from cancer studies, which depicts Yin side of MDSCs. In cancer, inherent immunosuppressive action of MDSCs favors tumor progression by inhibiting antitumor immune response. However, recently Yang side of MDSCs has also been worked out and suggests the role in maintenance of homeostasis during non-cancer situations like pregnancy, obesity, diabetes, and autoimmune disorders. Continued work in this area has armored the biological importance of these cells as master regulators of immune system and prompted scientists all over the world to look from a different perspective. Therefore, explicating Yin and Yang arms of MDSCs is obligatory to use it as a double edged sword in a much smarter way. This review is an attempt toward presenting a synergistic coalition of all the facts and controversies that exist in understanding MDSCs, bring them on the same platform and approach their "Yin and Yang" nature in a more comprehensive and coherent manner.

Keywords: myeloid derived suppressor cells, immunosuppression, immune regulation, epigenetics, homeostasis

\section{INTRODUCTION}

Originated from common hematopoietic progenitor cells, myeloid derived suppressor cells (MDSCs) encompasses a heterogeneous population of immature and mature myeloid cells possessing immunoregulatory activity. These cells suppress both the arms of immune system: innate and adaptive immunity of an individual. In normal and healthy individuals, immature myeloid cells (IMCs) get originated in bone marrow and further differentiate in mature granulocytes, macrophages or dendritic cells. Partial blockage of IMCs differentiation results in the discovery of MDSCs during various pathological conditions reported so far like cancer, trauma, stress, chronic inflammatory state. Substantial evidences suggest the importance of MDSCs in contribution to human malignancies, tumor progression, and metastasis. These cells play a key role in immunosuppression induced by tumor by inducing a state of tolerance $(1,2)$.

Most of our knowledge till date is mostly based on tumor models and cancer patients, but consistent interest of different fields in this area focused the relevance of these cells in non-cancer situations where over activated immune system need to be suppressed and wherein MDSCs proved as a boon for maintaining homeostasis in immune regulation (3). Due to the phenotypic and functional heterogeneity, the exact mechanism how MDSCs develop, accumulate, and function is still unveiling. Although originating from same precursor cells, they are known to suppress other cells of the same lineage. Possible epigenetic signatures involved in the above phenomena are also covered in this review. What epigenetics has to say about MDSCs recruitment and function is an emerging field of interest for scientists. 
Here our alluring goal is to review all the aspects of MDSCs that can give us a better clue to therapeutically target them in cancer and promote them in non-cancer situations. The crosstalk of the signaling pathways involved in the proliferation and accumulation of these cells has been discussed at length.

\section{ONTOGENY AND PHENOTYPIC CHARACTERIZATION OF MDSCs: APPEARANCES DO MATTER!!}

Originated from hematopoietic stem cells, "myeloid progenitors" or immature myeloid cells (IMC) migrate and get differentiated to mature granulocytes, macrophages or dendritic cells. It was in early 70's when accumulation of immune suppressive myeloid cells was associated with tumor progression. Till 2007, before the term 'myeloid derived suppressor cells (MDSCs) were coined, these immature cells were identified as: "immature myeloid cells (IMCs)," 'myeloid suppressor cells (MSCs) (4). Similar cells were later on reported in various other forms of cancer. Tumor produced vascular endothelial growth factor (VEGF) acts as a chemo attractant for these cells $(3,5)$. Transplanted tumors in mice also induced the production of these cells (6, 7) with similar activity of inhibiting antigen dependent $T$ cell activation (8).

Perplexing phenotypes of MDSCs provides both opportunities and frustrations for scientists. Phenotypic characterization of MDSCs became possible because of flow cytometry that senses distinguished cell surface markers on them. The phenotypic variability is dependent on the physiological as well as anatomic site of mice or human. Initially MDSCs in mice were defined as cells expressing cell surface markers $\mathrm{Gr}-1^{*} \mathrm{CD} 11 \mathrm{~b}+$ but lack the typical expression of mature macrophages and dendritic cells. MDSCs in mice are categorized in two major subsets: (i) Granulocytic MDSCs (G-MDSCs) having CD11b ${ }^{+}$Gr$1^{+} \mathrm{Ly6G}^{+} \mathrm{Ly}^{-} \mathrm{C}^{-}$cells surface markers and ii) Monocytic MDSCs (M-MDSCs) that present markers like CD11b + Gr-1 +Ly6G - Ly6C + on their cell surfaces $(4,9,10)$. Unlike mice, human MDSCs are characterized as $\mathrm{CD} 11 \mathrm{~b}^{+} \mathrm{CD} 33^{+} \mathrm{HLADR}^{-}$. Furthermore, $\mathrm{CD}_{1} 5^{+}$population correspond to G-MDSCs, and $\mathrm{CD}_{14}{ }^{+}$population correspond to M-MDSCs in addition to $\mathrm{CD}_{11 \mathrm{~b}}{ }^{+} \mathrm{CD}_{3}{ }^{+} \mathrm{HLADR}^{-}(11-16)$. Recently, a group discovered Lectin type oxidized receptor-1 (LOX-1) in humans as a new marker present on G-MDSCs. Further confirmation in mouse, blood, and spleen is needed for a unifying concept (17).

Because of the ambiguity in the expression of surface markers, many subsets of MDSCs do not exactly get classified into G/M MDSCs. Recently, a novel subset of MDSCs: fibrocytic MDSCs (F-MDSCs) appear to express $\mathrm{CD} 11 \mathrm{~b}^{\text {low }} \mathrm{CD} 11 \mathrm{c}^{\text {low }} \mathrm{CD} 33^{+} \mathrm{IL}-$ $4 \mathrm{R}^{+}$on their surfaces and might express HLA-DR unlike other human MDSCs (18-21). Although F-MDSCs show immunosuppressive behavior, but little is known about its differentiation and immunosuppressive mechanism (19). A drive that differentiates common progenitor cells into different subtypes of MDSCs and whether these MDSCs are really different from mature monocytes and neutrophils is a big question nowadays.
Available literature now gives a conclusive picture based on evidences like: (i) MDSCs have an intrinsic characteristic of immunosuppression (ii) in spite of growing mature monocytes and neutrophils with PAMPs, DAMPs or proinflammatory cytokines, they fail to show immunosuppressive activity (iii) MDSCs show distinctive genomic expression profile when compared to neutrophils (22). Inspite of these evidences, it still remains a question and needs to be further explicated.

\section{IMMUNOSUPPRESSIVE MECHANISMS: A DIFFERENT APPROACH}

MDSCs are immunologically activated cells. Apart from phenotypic heterogeneity, MDSCs display functional heterogeneity as well. The hallmark of MDSCs is their skill to suppress $\mathrm{T}$ cell and $\mathrm{NK}$ cell responses, inducing a state of tolerance. Interaction of MDSCs and T cells is not unidirectional where MDSCs control immune response and activation of T cells; and T cells affects MDSCs proliferation and suppressive behavior. Various $\mathrm{T}$ cell proliferation and activation suppressive mechanisms are known till date. Different subsets of MDSCs adopt different and specific strategies for exerting immunosuppressive activities. MDSCs produce factors like ROS, iNOS, Arginase-1, and IL-10 to combat against effector T cell responses. In this section, we will be discussing on the different mechanisms adopted by these cells to subdue our immune system. They are known to suppress our T cells in both antigen specific as well as antigen non-specific manner. Following section will let us know every possible mechanism these cells can undergo for immune surveillance.

\section{G-MDSCs Mediated Immunosuppression}

Enough evidences support the fact that different subsets of MDSCs adopt different mechanisms for immunosuppression. Likewise, G-MDSCs (i) use ROS as a tool for immunosuppression which requires more close cell to cell contact hence supports Ag specific $\mathrm{T}$ cell suppression (4, 11, 23-28). It disrupts the TCR/MHC complex formation $(11,16,23)$. ROS when interacts with NO, results in the formation of PNT. PNT induces apoptosis of T cells by nitrating the TCR $(11,28,29)$.

\section{M-MDSCs Mediated Immunosuppression}

In contrast to G-MDSCs, physical interaction is lessened in M-MDSCs and suppression is mainly dependent on iNOS, Arginase-1, and IL-10: (i) As arginine is a key nutritional substrate for $\mathrm{T}$ cell proliferation, Arginase-1 depletes arginine, producing urea, and ornithine (ii) iNOS produces $\mathrm{NO}$ and citrulline utilizing arginine and eventually inhibits $\mathrm{T}$ cell proliferation(30-32) (iii) iNOS induced NO downregulates JAK/STAT pathway resulting in $\mathrm{T}$ cell apoptosis (iii) IL10 induces activation of Foxp3 $+\mathrm{T}$ reg cells, induce antiinflammatory M2 macrophage differentiation and expansion of MDSCs population $(31,33-35)$. NO has a longer half-life than ROS and needs less closer contact, thus M-MDSCs act in a humoral way and suppress non-specific $\mathrm{T}$ cell responses. 


\section{F-MDSCs Mediated Immunosuppression}

The exact mechanism of differentiation and immunosuppression is not well-known in recently established subset of MDSCs. But it is supposed that acting through IDO (indoleamine oxidase); it induces $\mathrm{T}$ reg population and $\mathrm{M} 2$ macrophages population for $\mathrm{T}$ cell suppression $(20,21)$.

\section{EXPANSION, ACTIVATION AND MIGRATION OF MDSCs}

\section{Signal Initiators/Cytokines/Signal Initiation}

Our immune system has evolved mechanically to protect us from the deleterious effects of inflammation. One such strategy adopted by our immune system is the generation of immune suppressive cells like MDSCs from myeloid progenitors that offsets $\mathrm{T}$ cell action. The expansion, activation, and migration of these cells should be precisely synchronized reason being, as stated above they can be boon at one time and curse at the other. Several growth factors/cytokines are involved in MDSCs expansion, activation, and migration in both humans and mice, including M-CSF, GM-CSF, G-CSF, IL-13, IL-1ß or IL-6, TNF- $\alpha$, VEGF, PGE $_{2}$, proinflammatory $S 100$ proteins, C5a, LPS, PARP- $\gamma$, HSP72, Flt3L. They can act independently or in a synergistic manner. Depending on the concentration and microenvironment, they can be stimulatory and inhibitory mediator of immune system.

Discussing about the relevance of these growth factors, several animal studies has come up with beautiful results mainly in tumor model. G-CSF ${ }^{-/-}$or $\mathrm{G}_{-} \mathrm{CSFR}^{-/-}$mice turned neutropenic, while anti-G-CSF treatment was effective in inhibiting MDSCs infiltration near tumor site. Exogenous GCSF administration results in recruitment of MDSCs and shuts down innate immune system. A direct association is already established between G-CSF and G-MDSCs in tumor bearing mice (18). Where induction of G-CSF leads to tumor growth, it can act as a blessing during pregnancy and other pathological conditions which requires enough G-MDSCs to inhibit our innate immune system for leading a healthy life. Likewise, knockout studies for other cytokines like IL-1, M-CSF evidently provide a glimpse why and how these growth factors are important for MDSCs expansion, activation and migration (36).

Not just the cytokines are indispensable elements for MDSCs development, but the way they act is more important. Two theories have been proposed for expansion, activation and migration of MDSCs in tumor model: (i) "One signal hypothesis" states that one signal is enough for the differentiation of hematopoietic progenitor cells into MDSCs (ii) "Two signal hypothesis" states that the differentiation of HSC to MDSCs occurs in two steps: (i) HSC-IMC transition via STAT-3 signal on activation with cytokines like G-CSF,GM-CSF,IL-6,PGE2 and (ii) IMC-MDSCs transition mediated by mainly proinflammatory cytokines LPS, S100 proteins, IL-1 $B$ etc. and activating NFK-B, $\mathrm{PI} 3 \mathrm{~K}$, and STATs mediated signaling.

\section{Signaling and Crosstalk}

Although the exact signaling and molecular mechanism involved behind the generation of MDSCs is still evolving, it is believed that dysregulation happens somewhere in the canonical signaling pathway of myeloid development. We will be discussing the crosstalk among different signaling cascades initiating from the cytokines and how these growth factors independently or synergistically control the activation of MDSCs in different biological conditions. Targeting these pathways may clarify the mechanisms and help us in expanding or abolishing MDSCs when and wherever required. Schematic representation of different signaling cascades is elucidated in Figure 1.

\section{Ras Signaling}

Ras proteins are considered indispensable components of signaling pathways stemming from cell surface. Ras signaling has an important role to play in myeloid development. Ras protein cycles through "on" and "off" state depending on the binding of GTP and GDP, respectively. Under physiological states, this transformation is regulated by guanine nucleotide exchange factors (GEF) that promotes Ras activation and GTPase activating proteins (GAP) that accelerates Ras mediated GTP hydrolysis. Ras drives cell proliferation, survival and migration thus promoting tumors to attain a malignant phenotype via autonomous and non- autonomous mechanisms. Over activated mutant Ras alters proliferation and differentiating potential of macrophages. Oncogenic Ras promotes angiogenesis via VEGF and creates an immunosuppressive state by adopting methods to evade host anti-tumor response like: (i) reduced expression of MHC on cancer cells (ii) educating stroma to recruit macrophages or MDSCs at TME (37-40). Induction of MDSCs recruitment through Ras signaling via cytokine M-CSF is wellknown in cancer but need to be explored in other pathological conditions where Ras signaling plays crucial role in immune surveillance during disease development.

\section{PI3K/AKT Signaling}

A huge heterogeneity is present for the signaling proteins that binds to the phosphorylated phosphatidylinositol and based on these substrate specificities, PI3K has been divided into several classes. Cell type of the immune system determines which member of PI3K will be activated. Cytokines like PGE2, IL-2, IL-6, IL-7, GM-CSF, and interferons that regulate MDSCs development activate one of the classes of PI3K. Cytokines mentioned here have the potential to activate more than one signaling thus definitely a cross talk exists between PI3K/AKT signaling and other signaling cascades. A recent report proposed an unexplored connection between $\mathrm{PI} 3 \mathrm{~K} / \mathrm{AKT}$ and Wnt signaling discussed in detail below. A clue for PI3K/Akt mediated MDSCs regulation prompted other researchers to look into its signaling in detail. Selective disruption of various isoforms of PI3K showed altered phagocytic and chemotactic activity in vivo. Knock out studies in mice further validated the same in neutrophils (41). As regulating other cells, PI3K have the possibility to modulate MDSCs function as well. A study in aging mice with a defect in PI3K/Akt signaling contributed to compromised immune system and showed MDSCs accumulation in bone marrow and secondary lymphoid organs (42). The negative regulators of PI3K, i.e., SHIP (SH2 domain containing-5-inositol phosphatase) and PTEN 


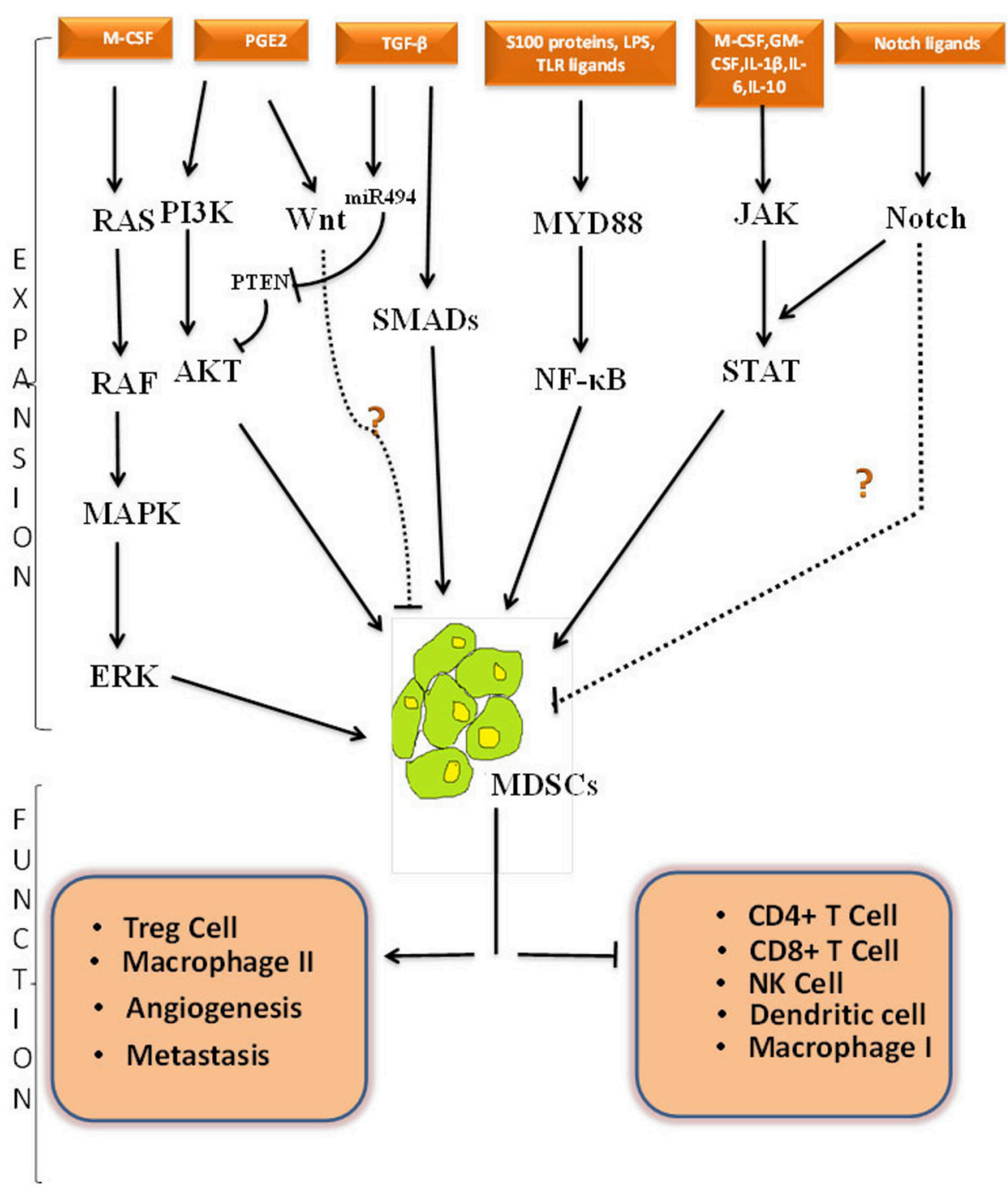

FIGURE 1 | Cross-talk among different signaling pathways involved in MDSCs expansion, activation and function. Schematic representation of possible pathways involved in MDSCs expansion, activation and function. Black solid line represents known pathway for MDSCs proliferation whereas black dotted line represents predicted pathway and crosstalk that can be involved in MDSCs regulation. How NOTCH pathway and Wnt pathway directly regulate MDSCs expansion is shown with a question mark. The positive and negative regulatory function of MDSCs is depicted in lower part of figure. PGE2, Prostaglandin E2; M-CSF, Macrophage colony stimulating factor; GM-CSF, Granulocyte-macrophage colony stimulating factor; IL-1ß, Interleukin 1 Beta; IL-6, Interleukin 6; IL-10, Interleukin 10; LPS,

Lipopolysacchharide;TGF- $\beta$, Transforming growth factor Beta; PI3K, Phosphoinositide 3-kinase; AKT-Protein kinase B, a serine threonine specific protein kinase; PTEN, Phosphatase and tensin homolog; MAPK, A mitogen-activated protein kinase; ERK, Extracellular Signal-regulated Kinase; JAK, Janus kinases; STAT, Signal transducer and activator of transcription; TLR, Toll like receptor; Myd88, Myeloid differentiation primary response 88; NF-k $\beta$, nuclear factor kappa-light-chain-enhancer of activated B; NK, natural killer cells; IFN- $\gamma$, Interferon gamma; Treg, T regulatory.

(phosphatase and tensin homolog) controls phosphoinoside metabolism in immune cells (43). Therefore, increasing the activity of SHIP may be beneficial in certain diseases like cancer, trauma, viral load or infection and harmful in situations where MDSCs are desirable for immune surveillance like pregnancy, obesity and diabetes. Based on the literature reported till date, PI3K pathway could be one of the major pathways involved in the regulation of MDSCs.

\section{JAK/STAT Signaling}

Inflammation is the complex state of biological response where immune system of our body acts against the invading pathogens.
The Janus kinase/Signal transducer and activator of transcription (Jak/Stat) pathway is well-known to regulate the inflammatory response. Jak family consists of four members: Jak1, Jak2, Jak3, and tyrosine kinase2 (Tyk2). Stat family is composed of seven members: Stat1, Stat2, Stat3, Stat4, Stat5a, and Stat5b. Jak could be activated by cytokine of IFN family members: $\alpha, \beta, \gamma$. Stat after getting phosphorylated and activated by Jak, translocates to the nucleus and acts as a transcriptional regulator. Few studies have shown Stat gets stimulated by M-CSF that is already stated as a growth inducing factor of MDSCs. So there must be some connection between activated Stat and MDSCs accumulation. MDSCs interfere with host immune system by 
inhibiting immune cell responsiveness toward IFN cytokines in tumors (44). Though Jak phosphorylation and Stat activation occurs through a variety of cytokines, but some specificity is still there depending on the type of immune cell and the isoform of Stat. In cancers, Stat along with NF-кB facilitates signal transduction coming from extracellular stimuli. Among all Stats, Stat3 plays a very crucial role in incidence of cancers. How this molecule regulates MDSCs activity by Arginase 1 was very well explained by Vasquez-dunddel et al. (45) where they reported that Arginase promoter has multiple binding sites for Stat3. si-RNA against STAT3 abolished MDSCs activity. A number of studies reported that constituent activation of Stat 3 promotes inflammation and tumor growth by expanding MDSCs population by upregulating Stat3 target genes like Bcell lymphoma XL(BCL-XL), cyclin D1, Myc, and survivin (4649). Being itself activated by proinflammatory cytokines like IL-4 or IL-6, Stat3 can downstream affects proinflammatory proteins like S100 family proteins (50). Although the precise mechanism is not yet elucidated but it is postulated that overexpression of S100 family proteins i.e., heterodimer of S100A8/S100A9 assisted NADPH oxidase complex formation which generates ROS and interferes with the differentiation of myeloid cells (28). An autocrine signaling exists as MDSCs also has receptors for S100 proteins on their cell surface and in turn these proteins help MDSCs migration toward TME. The mechanism needs further attention, as their signaling will definitely provide a link between inflammation and immune suppression theory. Other factor that negatively regulates Stat3 is IRF8 (Interferon regulatory factor 8). IRF-8 when overexpressed in mice lead to the reduction in MDSCs, acting as a negative regulator of Stat 3 and thus MDSCs (51). So targeting Stat 3 could be a therapeutic potential in cancers or wherever immunosuppression is harmful.

\section{TGF $\beta$ and PGE2/COX Signaling}

Talking of TGF $\beta$, an effective regulator of inflammatory response operates by affecting the activity of innate and adaptive immune cells. Depending on the cellular context and target genes, it can be a positive and negative regulator of transcription. TGF $\beta$ can regulate MDSCs proliferation via microRNA expression. A study showed miR494 deletion in MDSCs attenuated tumor growth. Still the exact signaling initiating from TGF $\beta$ involved in MDSCs expansion is not known in biological conditions apart from cancer.

Synthesized by COX-2, PGE2 possess both proinflammatory and immunosuppressive property. PGE2 signals through PGE2 receptor E-prostanoid (EP) in MDSCs $(52,53)$. Agonists of EP receptor including PGE2 stimulated bone marrow stem cells to generate MDSCs. Inhibition and in vivo administration of COX2 could significantly restore the differentiation of BM cells and reduce MDSCs accumulation, respectively (54). In total, we can say that PGE2 and COX-2 synergistically regulate the function and differentiating potential of MDSCs.

\section{Recent Studies Concerning MDSCs Regulation Notch signaling}

It is well-established that Notch signaling regulates differentiation and functions of myeloid derived cells like
DC, macrophages and mesenchymal stem cells $(55,56)$. In recent years, pleiotropic function of Notch has come up, where Notch is reported to modulate the immune responses by activating different immune cells. How Notch-RPB-J regulates MDSCs immunosuppressive behavior is explained by gain of function and loss of function experiments which proves that blockage of Notch pathway promoted the expansion of MDSCs with low immunosuppression (57). They unambiguously painted the regulatory axis of Notch Signaling as: Notch-IL6-STAT3-MDSCs. However, a lot more questions need to be addressed.

\section{Wnt signaling}

A well-established interaction between tumor and stroma is mediated by factors released either by tumor or by stroma. Tumor cells educate the stroma to recruit and maintain heterogeneous population of immature cells like MDSCs to potentially suppress $\mathrm{T}$ cell responses and promote tumor growth (47). Wnt pathway has been shown to antagonize differentiation of MDSCs and support the differentiation of mature DCs. $\beta$ catenin should be downregulated in MDSCs for them to get accumulated in mice as well as humans (58). But still a question rose, what drives downregulation of $\beta$ catenin in MDSCs. Is something to do with stroma? And the answer was yes. A protein Dickkopf-1, inhibitor of $\beta$ catenin dependent Wnt signaling is highly expressed in cancer cells and apart from its basic function, it inhibits $\beta$ catenin and promotes MDSCs accumulation (59, 60 ). Dysregulated $\beta$ catenin has been reported in many cancers but another study supported the above concept where PLC $\gamma 2-$ /- MDSCs display reduced $\beta$-catenin, and overexpression of $\beta$-catenin lessens tumor growth (58).

Wnt signaling has so much to do with human trophoblast invasion and differentiation (61). It is also reported to play role in human fetal growth in first and second trimester. How Wnt regulates MDSCs activity during pregnancy still remains a question of interest for researchers.

\section{EPIGENETIC CONTROL OF MDSCs}

In spite of originating from same population of cells, MDSCs keep a distinct ability to suppress other immune cells. It gives us a faint clue of changes in epigenetic signatures. Epigenetic mechanisms play a crucial role in gene expression and cellular differentiation. It defines all heritable modifications without any alteration in DNA sequence. DNA modifications, histone modifications and RNA interference initiates and sustain epigenetic regulatory network.

\section{DNA Modifications in MDSCs}

One of the most important DNA modifications is DNA methylation that mediates gene silencing with transcription machinery. DNA methyltransferases (DNMTs) aids both de novo and inherited DNA methylation which transfers methyl group to 5'position on cytosine residues with $\mathrm{CpG}$ islands (62). How DNA methylation regulates MDSCs expansion and biological activity is well-studied with the administration of $\Delta 9$ tetrahydrocannabinol (THC), a potent inducer of MDSCs. It 
enhanced promoter methylation of DNMT3a and DNMT3b and rescues arginase- 1 and Stat 3 expression $(63,64)$.

\section{Histone Modifications in MDSCs}

A form of epigenetic regulation where covalent modifications like acetylation, phosphorylation or ubiquitination alters the histone core structure and affects the binding efficiency of "effector molecules" on the DNA sequence. The best studied modification is acetylation. A dynamic balance between acetylation by HATs (histone acetyltransferases) and deacetylation by HDACs (histone deacetyltransferases) affects the gene expression (65). Does HDAC have any role to play in MDSCs expansion and activation impelled scientists to work in this area. Rosborough BR in 2012 reported that in-vitro or in-vivo administration of a naturally occurring antifungal metabolite TSA produced from Streptomyces having HDAC ability expands M-MDSCs in NOSand heme oxygenase (HO) ${ }^{-}$dependent manner (66). A new member of histone deacetylase family, HDAC11 seemed to serve as gatekeeper of myeloid differentiation and acts as a negative regulator of MDSCs expansion (67). Reports are there where mere inhibition of retinoblastoma gene via HDAC2, another histone deacetylase promoted switch of M-MDSCs to G-MDSCs in cancer, but lack immunosuppressive activity (68).

Epigenetic modifications may play a significant role in regulation of one of the most important transcription factors Stat3 in promoting MDSCs expansion and activation. Whether it regulates by phosphorylation or ubiquitination is not yet known. A recent study stated that p66, a component of
Mi2/NuRD/HDAC complex suppresses Stat3 phosphorylation (Y705) and ubiquitination (K63) by directly interacting Stat3 (69). Any regulatory mechanism controlling Stat3 activation will definitely be a new therapeutic potential against few pathological complications.

\section{miRNA Regulation of MDSCs}

In physiological conditions, miRNAs are well-known to regulate gene expression involved in cell development and differentiation. Emerging literature coming up with the idea that miRNAs are vitally involved in proliferation, development, migration and function of MDSCs.

MiR-210, miR-9, miR-690, miR-494, miR-155, miR-21, miR181b, miR-34a are known to epigenetically modify several promoters or genes and enhance immunosuppression mediated by MDSCs whereas miR-17-5p, miR-20a, miR-223, miR-146a, miR424, suppresses the suppressor (Table 1).

\section{siRNA Regulation of MDSCs}

Artificial double stranded RNA of nucleotide length 20-25, acts as a transcriptional regulator and trigger gene silencing. Several siRNAs are targeted to regulate MDSCs expansion, differentiation and activation e.g., A20si-RNA, Stat3si-RNA, Stem cell factor si-RNA, Casein kinase 2 si-RNA either induce apoptosis or promote differentiation of myeloid cells. These all strategies could improve immune therapy for treating advanced cancer or maintaining maternal-fetal tolerance during

TABLE 1 | Epigenetic regulation of MDSCs.

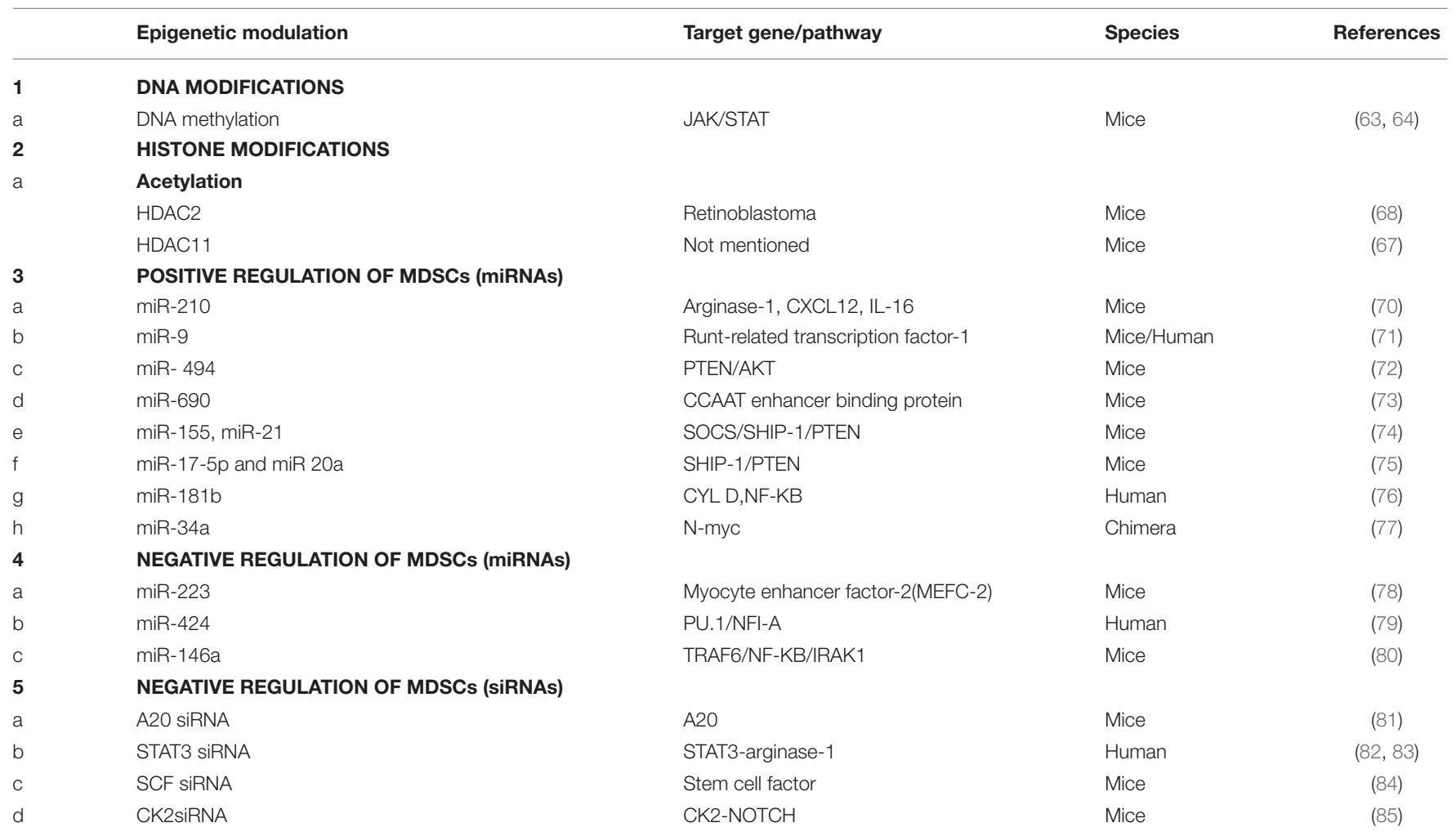


pregnancy. The mechanism how these siRNAs regulates MDSCs still remains an unanswered question.

\section{YIN AND YANG ARMS OF MDSCs}

When an antigen enters our body, inflammation occurs and subsequently innate immune system deals with it. Antigen presented by innate immune cells with respective MHCs recruits other adaptive immune cells for clearance of invading antigens and if immune system fails to complete the clearance of antigen successfully i.e., the host immune system is hijacked and misguided by the antigens, the situation creates an intricate mess of immune cells that is referred as chronic inflammation. To suppress the transition of acute to chronic inflammation, a negative feedback loop is required. This negative feedback is where Yang interaction of MDSCs comes into play. MDSCs have an inherent capability of immunosuppression either in acute or chronic inflammatory condition. Infiltration of immunosuppressive cells (MDSCs) at the site of inflammation aids in the suppression of transition from acute to chronic state. In a normal healthy individual, a balance of MDSCs and anti-inflammatory cytokines is in homeostasis with proinflammatory cytokines. Any imbalance in this immune homeostasis may lead to the occurrence and development of disease.

The differential behavior of MDSCs in acute and chronic inflammation is not anew. It behaves as double edged sword; in acute or regulated inflammatory situations, on one hand their accumulation beneficially lessens the burden of disease thus showing "Yang" behavior and on the other hand accumulation or depletion of MDSCs in dysregulated or chronic inflammatory settings enhances the burden of disease and show "Yin" behavior. The Yin role of MDSCs is to suppress our immune system up to a certain extent favoring the disease progression.

We need to discuss and draw a comparative picture of MDSCs and Tregs cells in parallel for having better insights into the immunosuppressive behavior of these cells. Treg cells are known for immunosuppression by restricting the proliferation and activation of effector T cells. Qiao et al. have very well-explained the Yin and Yang of T reg cells in autoimmune diseases (86). They discussed the pathogenesis of autoimmune disorder (AD) occurrence due to the breakdown of immune homeostasis via Tregs (Yin) whereas maintenance of immune homeostasis (Yang) in healthy individual which in retrospect provided the coherent articulation of understanding similar merits in MDSCs as well.

MDSCs are reported to change their fate and activity according the environment they are exposed to $(87,88)$. In one hand, they potentially enlighten the milieu of pregnancy, diabetes and prevent allograft rejection (89-91). On the other hand, tumor microenvironment (TME) promotes MDSCs accumulation that is a major obstacle for natural anti-tumor immunity and enhances tumor growth (92). These cells received much attention in recent 8-10 years due to its functional heterogeneity and outstanding immunomodulatory nature; hence they can be used as a new potential therapeutic target in different biological conditions. In this section, we tried to discuss what happens and why MDSCs showing their yin and yang role with special emphasis of which subset present in different biological conditions (Figure 2).

\section{Yin and Yang Role of MDSCs in Pregnancy and Related Complications}

The immune system of a pregnant female need to be modulated in a very well regulated way so that without compromising

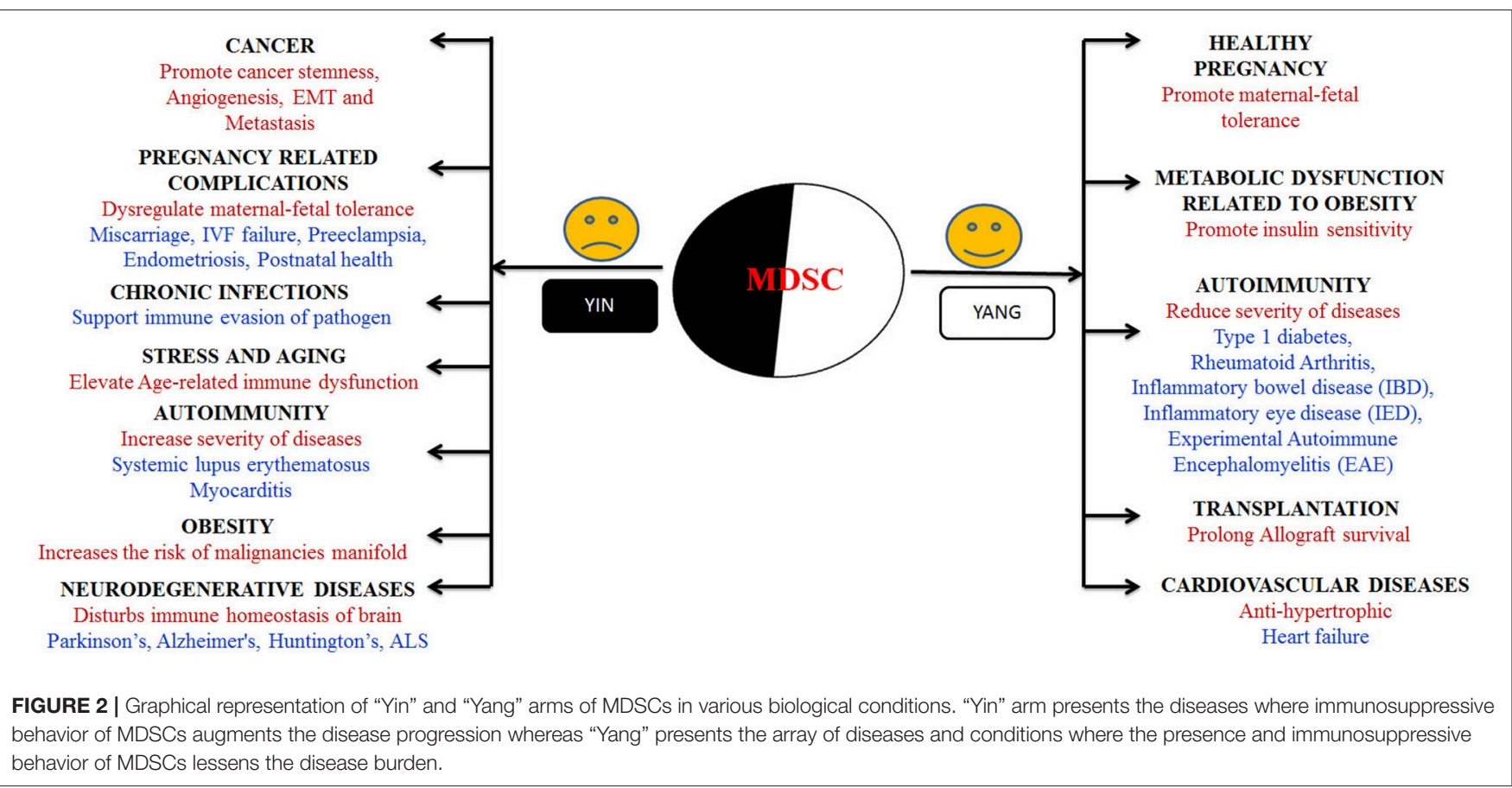


her own optimum immunity level, her immune system should simultaneously protect the semi-allogenic fetus from invading pathogens and confer tolerance from rejection. It has long been assumed that the maternal immunity must be compromised or redirected in a way to ensure a successful implantation and pregnancy. This state of modulation in maternal immune system is achieved by the synergistic interplay of regulatory cells like MDSCs and T regs.

Kostlin et al. reported that MDSCs especially G-MDSCs are significantly increased in healthy pregnant women during all stages of pregnancy compared to non-pregnant controls, implying their possible role in pregnancy (91). MDSCs are not only reported to regulate maternal fetal tolerance during pregnancy but are also well-known for $\mathrm{T}$ cell modulation and necessary for the control of inflammation. In line with the above study, our lab reported increased MDSCs in the first trimester compared to the third trimester of healthy pregnant women, proving its importance during implantation (93). On being investigated at the mechanistic aspect, MDSCs utilize multiple mechanisms to silence our overactive immune system during pregnancy: T cell anergy via secretion of ARG-1, iNOS, IDO, induction of other immunosuppressive cells (Tregs, uNK) and in-utero inflammation maintenance $(94,95)$. The significance of MDSCs showing the "Yang" role in healthy pregnancy tempted researchers to investigate their role in pregnancy related complications in the last few years.

Our lab works in the same direction and parallely reported that functionally suppressive MDSCs $(\mathrm{CD} 11 \mathrm{~b}+\mathrm{CD} 33+)$ are reduced in blood and endometrium of miscarriage patients (93). In another recent study, G-MDSCs were downregulated in IVF failures patients as well (96). A very recent literature showed pregnancy associated G-MDSCs and effector molecule Arg-I is significantly inhibited in pre-eclampsia patients with no difference in the population of Treg cells (97).

The scenario of pregnancy where MDSCs beautifully portray the Yang behavior, we cannot ignore the other side of the coin. Recent study in endometriosis reported elevated level of G-MDSCs as well as its immunosuppressive activity (ROS, Arginase I, suppress $\mathrm{T}$ cell proliferation) exaggerates endometrial lesions. This study was further confirmed when depletion of MDSCs with Gr-1 antibody in mice dramatically decreased endometrial lesions (98). Elevated level of G-MDSCs in cord blood of preterm born infants, modulating $\mathrm{T}$ cell responses suspects their role in regulating postnatal immunity dysfunction (99). The circulating levels of G-MDSCs are elevated in pre-term born neonates, modulate $\mathrm{T}$ cell responses and are necessary for control of inflammation (100). Till date, the studies discussed above corroborate Yin behavior of MDSCs in various gestational disorders, where elevated MDSCs disturb the immune homeostasis and helps in the development of disease. These noteworthy findings anticipate an important concept: Immune homeostatic milieu is essential for successful pregnancy. The breakdown of this homeostasis exposes the Yin behavior of MDSCs. Hence, these reports are fascinating researchers all around to shed light on these cells for exploring its regulatory nature in normal pregnancy vs. reproductive failure.

\section{Yin and Yang Role of MDSCs in Cancer}

Most of our knowledge about MDSCs till now comes from cancer studies. The presence of MDSCs with immunosuppressive activity is widely evident within the cancer sites since early 1900s. MDSCs not only promote tumor angiogenesis and invasion, but also impair anti-tumor innate and adaptive immune response; they are likely to subvert host immune surveillance; enhance the stemness of cancer cells and modifies pre-metastatic niche (11, 101-107). Accumulation of MDSCs in different tumors at tumor microenvironment induced by various chemokines is well-known but recently secretory IgM secreted by B cells is reported to accumulate MDSCs in chronic lymphocytic leukemia (CLL) (108). These studies suggest that MDSCs which was historically recognized as T cell suppressors; actually have additional potency to orchestrate more strategies for tumor progression and metastasis. Hence several cancer studies and tumor models present the "Yin" role of MDSCs where accumulation, expansion and activation of MDSCs create a permissive environment most suitable for the growth of malignant cells (106). Subset M-MDSCs are found to be remarkably high in multiple myeloma, leukemia hepatocellular carcinoma, prostate cancer and melanoma, while G-MDSCs are prominent in renal, colon, lung, breast and pancreatic adenocarcinoma $(1,109)$. Known to act solely as negative regulators of immune system, the Yang side of MDSCs is not yet reported as per our knowledge. Controversies do exist for the complex regulatory behavior of MDSCs in cancer at different stages. Most of the studies positively correlated the frequency of MDSCs with the cancer stage (110-112) while MDSCs are reported to be in inverse relation to the advanced stages of cancer. Moreover, contrary to other reports, tumor infiltrating MDSCs show reduced immunosuppressive behavior when compared to peripheral MDSCs (103). The comparative behavior of MDSCs in benign and malignant cancer still remains a hotspot research area which needs further exploration. This might clarify the discrepancy present in correlating MDSCs with stages of cancer. An immense focus is needed to reach to a unifying concept before inclusion of therapeutic targets into clinical practice (113).

Treatment of cancer is a challenging issue for both scientists and clinicians. Common cancer treatments known to us include surgery, radiotherapy, chemotherapy, and endotherapy. Targeting MDSCs via radio or chemotherapy is effective upto a limited extent but fail to provide long term benefits. MDSCs may weaken the anti-tumor effect of cancer vaccines but effective response of vaccines increases when used in conjunction with MDSCs inhibition. They collectively adopt different mechanisms for MDSCs inhibition: (i) deactivation (PDE5, histone deacetylase, NO inhibitors, Arginase inhibitors, ROS inhibitors, STAT3 inhibitors) (ii) inhibition of recruitment at the site of tumor (CCR5 antagonist, CCL2 inhibitor) (iii) differentiation (ATRA, Vitamin A, D3) (iv) Regulation of myelopoiesis and depletion (Tyrosine kinase inhibitors, cytotoxic agents, anti Hsp90) (107, 114, 115). Recently, liver-X nuclear receptor (LXR) agonism i.e., GW3965/RGX-104 and a long non-coding RNA i.e., Lnc-chop are also used to regulate 
immunosuppressive function of MDSCs as well as its abundance in tumor environment $(116,117)$. Targeting MDSCs still remains a challenging task because of the heterogeneity and lack of specific marker $(118,119)$.Immunotherapy is another promising and encouraging strategy for cancer treatment. Immune checkpoint inhibition immunotherapy is popular therapy nowa-days with low toxicity levels and provides long term survival benefits. As, immune check points are basically involved in maintenance of self-tolerance, assistance and regulation of immune response. Immune checkpoint therapies (ICTs) act on both the stimulatory or inhibitory pathways and activate the immune system against cancer. The most common inhibitory pathways are programmed death cell protein-1/programmed death cell ligand-1 [PD-1/L1] and cytotoxic $\mathrm{T}$ lymphocyte antigen-4 [CTLA-4] and stimulatory pathway are OX40 (TNFR; Tumor necrosis factor receptor), Inducible co-stimulator (), Glucocorticoid-induced TNF receptor family-related protein (GITR), 41BB (CD137), CD40. Nivolumab, Pembrolizumab and Ipilimumab are the antagonist agents used as immune checkpoint inhibitors. MOXR-0916, AMG-228, JTX-2011, Utomilumab, CP870893, APX005M, ADC-1013, lucatumumab, Chi Lob 7/4, dacetuzumab, SEA-CD40 are the agonist agents used for targeting the stimulatory pathway. Recently, Ipilimumab have been used for treatment of melanoma cancer patients. Ipilimumab directly affects the count and immunosuppressive function of MDSCs. Recent studies also suggest that cancer patients become resistant to antibodies targeted against these immune checkpoints due to the presence of MDSCs at the site of tumor. MDSCs hinder the activity of ICTs so it could be a favorable target during combination therapy. Despite the efficiency of ICTs in unleashing immune system and maintaining self- tolerance, they sometimes pose a threat to a range of auto immune disorders. (120-125). A question rises if ICI therapy can increase the risk of autoimmune diseases, blocking of MDSCs based therapy can also raise the same question. Literature is sparse in this field and no report till today says about the risk of autoimmunity that may occur on blockade of MDSCs expansion, recruitment, activation or MDSCs when combined with ICTs. The need of the hour is to revisit the immunological aspect of MDSCs origin for suitable answer to this query. Question about the varied response of ICTs remains unanswered too. Though promising, but inconsistency in the results did not allow us to reach to a conclusion about ICTs alone or in combination with other drugs $(126,127)$. Recently, combination strategy has been applied in murine model of renal and lung carcinoma where etinostat enhanced the efficacy of PD-1 targeted immune therapy $(120,128)$. Further studies are warranted in upcoming years to develop an efficient strategy for the treatment of cancer patients.

\section{Yin and Yang Role of MDSCs in Autoimmunity}

The involvement and expansion of MDSCs in both human and murine models of autoimmune diseases is clearly evident. Contradictions persist due to varied heterogeneity in terms of action and effect of MDSCs in different autoimmune disorders, a plausible comprehensive theory is still not valid in this disease (129). In vitro expanded MDSCs keep the potential to clear inflammatory tissue by regulating and promoting the expansion of other immunosuppressive population of Tregs. They significantly inhibit Th1 and Th17 immune responses and thus the severity of diseases in models of rheumatoid arthritis (RA), inflammatory bowel disease (IBD), inflammatory eye disease (IED), experimental autoimmune encephalomyelitis (EAE), and Type 1 diabetes (130). In all the above mentioned autoimmune diseases, MDSCs outperform as "Yang" player of the team. Recently, two drugs, Cannabidiol, Glatiramer acetate are used for the enhancement of MDSCs dependent Tregs cell generation and reduction of pro-inflammatory cytokine secretion in IBD, Multiple sclerosis mice model $(131,132)$.

Contrasting theories are also present which suggest that there might be proinflammatory angle to MDSCs which conventionally have an anti-inflammatory behavior in almost all cases. In case of RA, a report suggests, that MDSCs have found to portray a rather unconventional pro-inflammatory behavior during the early stages of the Arthritis $(133,134)$. In addition, a recent citation for behavior of MDSCs in RA also suggests that depletion in the number of MDSCs during the early stages of RA causes a weaker inhibition of $\mathrm{T}$ cells thereby causing pro-inflammatory response, which in this case is an indirect representation. Due to the lack of more evidence and other substantial literary representations it still remains unclear whether the anti-inflammatory role has become proinflammatory or the shift has been caused indirectly by T-cell due to change in the population of MDSCs(95). Therefore, the immune regulation via MDSCs in RA still remains elusive.

Contrary and apart from Yang nature of MDSCs, they also show "Yin" behavior in various autoimmune disorders such as Systemic lupus erythematosus (SLE) and Myocarditis. These cells expand in patient's blood and its frequency is directly correlated with IL-17 producing Th-17 cells and severity of diseases (95). The risk of autoimmunity associated with immune checkpoint therapy used in cancer is also due to the Yin behavior of MDSCs $(120,121)$. Strong correlations do exist between cancer and autoimmunity that need to be considered further. This correlation might be beneficial in answering the queries related to pathophysiology of autoimmune disorders.

\section{Yin and Yang Role of MDSCs in Stress and Aging}

With age, the immune system gets remodeled: the process termed as immunosenescence. Both the arms of immune system: innate and adaptive gets compromised and a person becomes susceptible to various pathological conditions like cancer, autoimmunity, and infections. Inflammageing: Increase in systemic inflammation is a well-documented feature of aging where the regulatory mechanism of immune system gets hampered. Impairment in responding to stress is another feature of aging. One of the possible reasons of this compromised immunity in elderly people can be our immune suppressive MDSCs (135). Recent publications have positively correlated stress and aging with MDSCs in both aged human and mice but which specific subset of MDSCs is involved here is still a 
perplexing question. Recent study has shown that both natural and augmented aging in mice drives an expansion of MDSCs through NF- $\kappa \mathrm{B}$ dependent pathway (136). In these conditions, increased MDSCs population worsens the disease severity by aggravating type 2 responses and alleviating age-related immune dysfunction ("Yin" of MDSCs). The dysregulation of immune homeostasis and poor response to vaccines may be due to the accumulation of MDSCs. Till date, Yang role of MDSCs is not seen in aged people. Further research is now needed to target MDSCs for the proper regulation of immune system.

\section{Yin and Yang Role of MDSCs in Obesity}

Obesity is a chronic low-grade inflammatory disease and is linked with several immunological disorders. Pro-inflammatory milieu in adipose tissue mimics that in tumor microenvironment with the same constellation of molecules. Studies till now states that chronic inflammation of adipose tissue in obese mice/ human drives the accumulation of MDSCs and thus increases the rate of malignancies many fold when compared to lean controls ("Yin" of MDSCs)(137-139). Obesity promotes immunosuppressive environment by accumulating MDSCs both at local and systemic level via production of chemokine factor CCL2. Experimental data tells us that M-MDSCs and G-MDSCs are accumulated in obese mice whereas M-MDSCs are elevated in humans (138). Very recently, the "Yang" behavior of MDSCs came into consideration when they showed protective role against some of the metabolic dysfunctions associated with obesity in contrast to exclusive detrimental role of tumor induced MDSCs (140). Surprisingly, obesity driven MDSCs decreased blood glucose levels and lessened the burden of insulin tolerance. This unusual behavior of MDSCs in obesity leaves us with questions in our mind asking how they exceled in showing their Yin and Yang sides simultaneously. The mechanistic study need to be explored with the aim to counteract its detrimental role over beneficial role.

\section{Yin and Yang Role of MDSCs in Transplantation}

Treg cells were the key players in controlling allograft rejection till researchers discovered the beneficial and desirable role of MDSCs were discovered in various inflammatory conditions like solid organ transplantation, dipping unwanted immune system(141). Since MDSCs shield tumor antigens from recognition, they are closely associated in induction and maintenance of immune tolerance toward organ transplantation(142, 143). Interacting with network of other immune cells, MDSCs regulate host immune system managing allograft survival ("Yang" of MDSCs) (144). It was widely reported that M-MDSCs accumulated during bone marrow, kidney and heart transplantation whereas the subset of MDSCs remains unidentified in skin transplantation. It has been predicted that MDSCs infiltration toward graft can suppress the incidence or severity of graft-vs.-host disease (GVHD) (145). Recent studies further prove this anticipation. Intestinal Transplant (IT) recipients accumulates MDSCs and suppress $\mathrm{T}$ cell immune response toward donor antigen (146). Accumulation of M-MDSCs as well as Tregs is reported to enhance graft survival in Almost Tolerant Kidney Transplant Recipient (ATKTR) individuals (147). A recent report has shown Dexamethasone induced Myeloid-Derived suppressor cells prolong allocardiac graft survival through iNOS and glucocorticoid receptor-dependent mechanism (148). MDSCs based cell therapy aids in prolonging graft survival and transplantation tolerance reflects the "Yang" behavior of MDSCs. A tight regulation of cell therapy in terms of time and contact is prerequisite else over activation of MDSCs may result in complications such as infection or tumor development showing the "Yin" behavior of MDSCs (141). The Yin and Yang behavior is also dependent on the differential effect of immunosuppressive drugs on MDSCs during implantation. Some drugs significantly augment the function of MDSCs, some diminish and still some remains unexplored. The negative effects of these agents may diminish the tolerance induction $(88,149)$.

The recent advances and importance of MDSCs has garnered scientists to explore about MDSCs proliferation, differentiation and activation in clinical investigations during allograft transplantation. Studies until recently are there in invitro models or animal models, and it gives a platform for researchers to explore the mechanism involved in tolerance induction.

\section{Yin and Yang Role of MDSCs in Chronic Infections}

On the attack of pathogens, MDSCs acting as anti-inflammatory tool tries to bring peace between host and pathogen by maintaining immune homeostasis. Cancer and infections are homologous and share common pathophysiology that pushes the hematopoietic system and guides the expansion of MDSCs. Inflammation gets awry and pathogenic during the chronic phase of infection. The progression of disease during chronic infections is directly proportional to the expansion of MDSCs. Recent reports indicated the expansion of MDSCs in various chronic infections caused by bacteria, virus, parasites and fungi. Mostly, M-MDSCs is reported to get expanded in infections caused by Gram-positive bacteria (M. tuberculosis, Staphylococcus aureus), Gram negative bacteria (Klebsiella pneumonia, Helicobacter pylori, Escherichia coli), polymicrobial sepsis, virus (Hepatitis B virus, HBV soluble antigen, Hepatitis C virus, Human immunodeficiency virus, Influenza A virus, Virus murine acquired immune deficiency syndrome (AIDS), Murine herpesvirus 68) (150). Along with Tregs and IL-10, MDSCs were elevated in viral infection caused due to Japanese encephalitis virus (JEV). JEV induced MDSCs keep the potential to suppress T cells (specifically T[follicular]), splenic and plasma B cells (151) However, particular subset of MDSCs involved in infections caused by Vesicular stomatitis Indiana virus (VSV), adenovirus, Vaccinia, Pulmonary hypertension ( $\mathrm{PH})$, Chronic Obstructive Pulmonary Disease (COPD) is yet an enigma (152-154). Zang et al. showed a positive correlation of MDSCs in patients with primary biliary cholangitis (PBC), a type of liver inflammation. They also found high expression of cysteine-rich protein 61 (CCN1) in impaired cholangiocytes and hepatocytes, which regulates expansion and immunosuppressive function of MDSCs 
(155). Recent studies reported the involvement of G-MDSCs in $\mathrm{T}$ cell proliferation and Th2 cytokine production during prosthetic joint infection (PJI). Mechanistically, PJI induced GMDSCs mainly reduces chronicity of infection by inhibition of pro-inflammatory cytokine production and anti-microbial actions of cytotoxic immune effector cells (156).

Thus, the survival or clearance of invading pathogen depends largely on the nature of pathogen and the duration of infection. It thus decides whether MDSCs reflect their beneficial role, where they show host protective behavior ("Yang") (157-159) or harmful role, where they increases the disease burden ("Yin") (160-162).

A better understanding is further needed to explain MDSCs regulation of host pathogen interaction which will give us a clearer picture about their therapeutic application.

\section{MDSCs in Other Miscellaneous Conditions}

Any pathological condition that encompasses inflammatory component provides us a clue and open questions to explore its disturbed immune homeostasis and the potential role of MDSCs. One of the common factors in chronic inflammation associated disorder is immunosuppression. Recent reports present the microenvironment of Alzheimer's patient brain as immunosuppressive, where various chemokines and cytokines secreted by $\mathrm{AD}$ brains keep the potential for recruitment and activation of MDSCs which promotes the deposition of $\mathrm{AB}$ plaques and is thus involved in its pathology. The exact mechanism of immunosuppression is still not explored much (163). Studies on other neurological disorders like amyotrophic lateral sclerosis (ALS), Parkinson's disorder and Huntington's disease also reports the presence of elevated MDSCs but the exact immune mechanism involved is still a question that needs to be answered $(164,165)$. Apart from detrimental role of MDSCs ("Yin") in neurodegenerative diseases, they exhibit cardio protective role ("Yang") in heart failure patients. Through the secretion of IL-10 and NO, these immune suppressive cells act as anti-hypertrophic and anti-inflammatory molecule. Adoptive transfer of MDSCs alleviates the cardiac dysfunction (166).

\section{CONCLUDING REMARKS}

The hyper-flexible nature of MDSCs has been enthralling scientific community especially over the last 15 years. Even

\section{REFERENCES}

1. Kumar V, Patel S, Tcyganov E, Gabrilovich DI. The nature of myeloid-derived suppressor cells in the tumor microenvironment. Trends Immunol. (2016) 37:208-20. doi: 10.1016/j.it.2016.01.004

2. Nagaraj S, Youn J-I, Gabrilovich DI. Reciprocal relationship between myeloid-derived suppressor cells and T cells. J Immunol. (2013) 191:17-23. doi: 10.4049/jimmunol.1300654

3. Han S, Yang Y. Phenotypic and functional dissection of myeloidderived suppressor cells. Appl Biol Chem. (2016) 59:367-71. doi: 10.1007/s13765-016-0172-9

4. Youn J-I, Nagaraj S, Collazo M, Gabrilovich DI. Subsets of myeloid-derived suppressor cells in tumor bearing micel. though we have understood the functionality of MDSCs on an immuno-suppressive and anti-inflammatory level but that development has been in retrospect of cancer studies done over the last decade. We still lag behind in developing methods to modulate the phenotypic responses proactively and we have only been able to define the levels of MDSCs and categorized them.

MDSCs shift their functional phenotypic response as per the given environmental stimuli. On one hand, it enlightens the milieu of pregnancy, where it is crucial during 1st trimester of pregnancy during implantation process; on the other hand it constrains our immune system's response toward developing tumors, and reduces anti-tumor immunity.

With the functional understanding of M-MDSCs and GMDSCs, we are now able to identify on surface the plasticity of these cells in various types of cancers and in various stages of pregnancy. However, there are still patches of missing information to completely understand the molecular functional mechanisms in differentiation of MDSCs.

The key take home message of this article is to understand how these MDSCs behave as a double edged sword in different pathological conditions. The various diseases and conditions mentioned have been studied from both aspects of beneficial and detrimental effects of MDSCs. Their behavior is critical into unlocking significant clinical and therapeutic progressions in the field of medicine.

With extra-ordinary work going on all around, in few years we would be able to mine the pertinent information to able to identify the markers of these cells and develop precision targeting, opening up interesting areas of research and experimentation in domains for pro-active immune surveillance.

\section{AUTHOR CONTRIBUTIONS}

KS, SB, PV, and SR contributed in the conception and design of the review. SB wrote the first draft of the manuscript. PV contributed in writing the sections of the review. RV helped in critically revising the review for intellectual content.

\section{ACKNOWLEDGMENTS}

SB is sincerely thankful to CSIR-UGC for financial assistance in the form of fellowship. PV is sincerely thankful to DBT for financial assistance in the form of fellowship. 
8. Monu NR, Frey AB. Myeloid-derived suppressor cells and anti-tumor T cells: a complex relationship. Immunol Invest. (2012) 41:595-613. doi: 10.3109/08820139.2012.673191

9. Sica A, Bronte V. Altered macrophage differentiation and immune dysfunction in tumor development. J Clin Invest. (2007) 117:1155-66. doi: $10.1172 /$ JCI31422

10. Movahedi K, Guilliams M, Van Den Bossche J, Van Den Bergh $\mathrm{R}$, Beschin A, De Baetselier $\mathrm{P}$, et al. subpopulations with distinct $\mathrm{T}$ cell - suppressive activity Identification of discrete tumor-induced myeloid-derived suppressor cell subpopulations with distinct $\mathrm{T}$ cell suppressive activity. Blood (2012) 111:4233-44. doi: 10.1182/blood-2007-07099226

11. Nagaraj S, Gabrilovich DI. Myeloid-derived suppressor cells in human cancer. Cancer J. (2010) 16:348-53. doi: 10.1097/PPO.0b013e3181eb3358

12. Greten TF, Manns MP, Korangy F. Myeloid derived suppressor cells in human diseases. Int Immunopharmacol. (2011) 11:802-6. doi: 10.1016/j.intimp.2011.01.003

13. Dumitru CA, Moses K, Trellakis S, Lang S, Brandau S. Neutrophils and granulocytic myeloid-derived suppressor cells: immunophenotyping, cell biology and clinical relevance in human oncology. Cancer Immunol Immunother. (2012) 61:1155-67. doi: 10.1007/s00262-012-1294-5

14. Filipazzi P, Huber V, Rivoltini L. Phenotype, function and clinical implications of myeloid-derived suppressor cells in cancer patients. Cancer Immunol Immunother. (2012) 61:255-63. doi: 10.1007/s00262-011-1161-9

15. Poschke I, Kiessling R. On the armament and appearances of human myeloid-derived suppressor cells. Clin Immunol. (2012) 144:250-68. doi: 10.1016/j.clim.2012.06.003

16. Meirow Y, Kanterman J, Baniyash M. Paving the road to tumor development and spreading: Myeloid-derived suppressor cells are ruling the fate. Front Immunol. (2015) 6:523. doi: 10.3389/fimmu.2015.00523

17. Gabrilovich DI. Myeloid-derived suppressor cells. (2018) 5:3-8. doi: 10.1158/2326-6066.CIR-16-0297

18. Abrams SI, Waight JD. Identification of a G-CSF-Granulocytic MDSC axis that promotes tumor progression. Oncoimmunology (2012) 1:550-1. doi: 10.4161/onci.19334

19. Zhang H, Maric I, DiPrima MJ, Khan J, Orentas RJ, Kaplan $\mathrm{RN}$, et al. Fibrocytes represent a novel MDSC subset circulating in patients with metastatic cancer. Blood (2013) 122:1105-13. doi: 10.1182/blood-2012-08-449413

20. Zoso A, Mazza EMC, Bicciato S, Mandruzzato S, Bronte V, Serafini P, et al. Human fibrocytic myeloid-derived suppressor cells express IDO and promote tolerance via Treg-cell expansion. Eur J Immunol. (2014) 44:330719. doi: 10.1002/eji.201444522

21. Gunaydin G, Kesikli SA, Guc D. Cancer associated fibroblasts have phenotypic and functional characteristics similar to the fibrocytes that represent a novel MDSC subset. Oncoimmunology (2015) 4:1-9. doi: 10.1080/2162402X.2015.1034918

22. Condamine T, Dominguez GA, Youn J-I, Kossenkov A V, Mony S, AliceaTorres K, et al. Lectin-type oxidized LDL receptor-1 distinguishes population of human polymorphonuclear myeloid-derived suppressor cells in cancer patients. Sci Immunol. (2016) 1:aaf8943. doi: 10.1126/sciimmunol.aaf8943

23. Kusmartsev S, Nefedova Y, Yoder D, Gabrilovich DI. Antigen-specific inhibition of $\mathrm{CD} 8+\mathrm{T}$ cell response by immature myeloid cells in cancer is mediated by reactive oxygen species. J Immunol. (2004) 172:989-99. doi: 10.4049/jimmunol.172.2.989

24. Sinha P, Clements VK, Ostrand-Rosenberg S. Interleukin-13-regulated M2 macrophages in combination with myeloid suppressor cells block immune surveillance against metastasis. Cancer Res. (2005) 65:11743-51. doi: 10.1158/0008-5472.CAN-05-0045

25. Nefedova Y, Fishman M, Sherman S, Wang X, Beg AA, Gabrilovich DI. Mechanism of all-trans retinoic acid effect on tumor-associated myeloid-derived suppressor cells. Cancer Res. (2007) 67:11021-8. doi: 10.1158/0008-5472.CAN-07-2593

26. Ando T, Mimura K, Johansson CC, Hanson MG, Mougiakakos D, Larsson $\mathrm{C}$, et al. Transduction with the antioxidant enzyme catalase protects human $\mathrm{t}$ cells against oxidative stress. J Immunol. (2008) 181:8382-90. doi: 10.4049/jimmunol.181.12.8382
27. Markiewski MM, DeAngelis RA, Benencia F, Ricklin-Lichtsteiner SK, Koutoulaki A, Gerard C, et al. Modulation of the antitumor immune response by complement. Nat Immunol. (2008) 9:1225-35. doi: 10.1038/ni.1655

28. Corzo CA, Cotter MJ, Cheng P, Cheng F, Kusmartsev S, Sotomayor $\mathrm{E}$, et al. Mechanism regulating reactive oxygen species in tumorinduced myeloid-derived suppressor cells. J Immunol. (2009) 182:5693-701. doi: 10.4049/jimmunol.0900092

29. Raber PL, Thevenot P, Sierra R, Wyczechowska D, Halle D, Ramirez ME, et al Subpopulations of myeloid-derived suppressor cells impair $\mathrm{T}$ cell responses through independent nitric oxide-related pathways. Int J Cancer (2014) 134:2853-64. doi: 10.1002/ijc.28622

30. Rodriguez PC, Quiceno DG, Ochoa AC. L-arginine availability regulates T-lymphocyte cell-cycle progression. Blood (2007) 109:1568-73. doi: 10.1182/blood-2006-06-031856

31. Rodriguez PC, Ernstoff MS, Hernandez C, Atkins M, Zabaleta J, Sierra R, et al. Arginase I-producing myeloid-derived suppressor cells in renal cell carcinoma are a subpopulation of activated granulocytes. Cancer Res. (2009) 69:1553-60. doi: 10.1158/0008-5472.CAN-08-1921

32. Oberlies J, Watzl C, Giese T, Luckner C, Kropf P, Muller I, et al. Regulation of NK cell function by human granulocyte arginase. J Immunol. (2009) 182:5259-67. doi: 10.4049/jimmunol.0803523

33. Blancho G. Myeloid-derived suppressor cells : mechanisms of action and recent advances in their role in transplant tolerance. Front Immunol. (2012) 3:208. doi: 10.3389/fimmu.2012.00208

34. Sinha P, Clements VK, Bunt SK, Albelda SM, Ostrand-rosenberg S. Crosstalk between myeloid-derived suppressor cells and macrophages subverts tumor immunity toward a type 2 response. J Immunol. (2007) 179:977-83. doi: 10.4049/jimmunol.179.2.977

35. Heim CE, Vidlak D, Scherr TD, Hartman CW, Garvin KL. Interleukin12 promotes myeloid-derived suppressor cell ( MDSC ) recruitment and bacterial persistence during S . aureus orthopedic implant infection. Immunol. (2016) 194:3861-72. doi: 10.4049/jimmunol.1402689

36. Zhou Z, French DL, Ma G, Eisenstein S, Chen Y, Divino CM, et al. Development and function of myeloid-derived suppressor cells generated from mouse embryonic and hematopoietic stem cells. Stem Cells (2010) 28:620-32. doi: 10.1002/stem.301

37. Lohmann S, Wollscheid U, Huber C, Seliger B. Multiple levels of MHC class I down-regulation by ras oncogenes. Scand J Immunol. (1996) 12:537-44.

38. Seliger B, Harders C, Lohmann S, Momburg F, Tamp R. Down-regulation of the MHC class I antigen- processing machinery after oncogenic transformation of murine fibroblasts. Eur J Immunol. (1998)122-33.

39. Clark CE, Hingorani SR, Mick R, Combs C, Tuveson DA, Vonderheide RH. Dynamics of the immune reaction to pancreatic cancer from inception to invasion. Cancer Res. (2007) 67:9518-28. doi: 10.1158/0008-5472.CAN-07-0175

40. Dupage M, Cheung A, Mazumdar C, Winslow MM, Bronson R, Schmidt LM, Crowley D, Chen J, Jacks T. Endogenous T cell responses to antigens expressed in lung adenocarcinomas delay malignant tumor progression. Cancer Cell (2011) 19:72-85

41. Hirsch E, Katanaev VL, Garlanda C, Azzolino O, Pirola L, Silengo $\mathrm{L}$, et al. Central role for $\mathrm{G}$ protein-coupled phosphoinositide 3-kinase $\gamma$ in inflammation. Science (2000) 287:1049-53. doi: 10.1126/science.287.5455.1049

42. Enioutina EY, Bareyan D, Daynes RA. A role for immature myeloid cells in immune senescence. J Immunol. (2011) 186:697-707. doi: 10.4049/jimmunol.1002987

43. Cully M, You H, Levine AJ, Mak TW. Beyond PTEN mutations : the PI3K pathway as an integrator of multiple inputs during tumorigenesis. Nat Rev Cancer (2006) 6:184-92. doi: 10.1038/nrc1819

44. Trikha P, Carson WE. Signaling pathways involved in MDSC regulation. Biochim Biophys Acta (2015) 1846:55-65. doi: 10.1016/j.bbcan.2014. 04.003

45. Vasquez-dunddel D, Pan F, Zeng Q, Gorbounov M, Albesiano E, $\mathrm{Fu}$ J. STAT3 regulates arginase-I in myeloid-derived suppressor cells from cancer patients. J Clin Invest. (2013) 123:1580-9. doi: 10.1172/ JCI60083 
46. Kujawski M, Kortylewski M, Lee H, Herrmann A, Kay H, Yu H. Stat3 mediates myeloid cell - dependent tumor angiogenesis in mice. J Clin Invest. (2008) 118:3367-77. doi: 10.1172/JCI35213

47. Mace TA, Ameen Z, Collins A, Wojcik S, Mair M, Young GS. Pancreatic cancer-associated stellate cells promote differentiation of myeloid-derived suppressor cells in a STAT3-dependent manner. Cancer Res. (2014) 73:300718. doi: 10.1158/0008-5472.CAN-12-4601

48. Xin H, Zhang C, Herrmann A, Du Y, Figlin R, Yu H. Sunitinib inhibition of Stat3 induces renal cell carcinoma tumor cell apoptosis and reduces immunosuppressive cells. Cancer Res. (2010) 69:2506-13. doi: 10.1158/0008-5472.CAN-08-4323

49. Wu L, Wang G, Qu P, Yan C, Du H. Overexpression of dominant negative peroxisome proliferator-activated receptor- $\gamma(\operatorname{PPAR} \gamma)$ in alveolar type II epithelial cells causes inflammation and T-cell suppression in the lung. Am J Pathol. (2011) 178:2191-204. doi: 10.1016/j.ajpath.2011.01.046

50. Sinha P, Okoro C, Foell D, Freeze HH, Ostrand-Rosenberg S, Srikrishna G. Proinflammatory $\mathrm{S} 100$ proteins regulate the accumulation of myeloid-derived suppressor cells. J Immunol. (2008) 181:4666-75. doi: 10.4049/jimmunol.181.7.4666

51. Waight JD, Netherby C, Hensen ML, Miller A, Hu Q, Liu S, Bogner PN. Myeloid-derived suppressor cell development is regulated by a STAT/IRF-8 axis. J Clin Invest. (2013) 123:4464-78. doi: 10.1172/JCI68189

52. Rodriguez PC, Hernandez CP, Quiceno D, Dubinett SM, Zabaleta J, Ochoa $\mathrm{JB}$, et al. Arginase I in myeloid suppressor cells is induced by COX-2 in lung carcinoma. J Exp Med. (2005) 202:931-9. doi: 10.1084/jem.20050715

53. Zhang Y, Liu Q, Zhang M, Yu Y, Liu X, Cao X. Fas signal promotes lung cancer growth by recruiting myeloid-derived suppressor cells via cancer cell-derived PGE2. J Immunol. (2009) 182:3801-8. doi: 10.4049/jimmunol.0801548

54. Eruslanov E, Daurkin I, Ortiz J, Vieweg J, Kusmartsev S. Pivotal advance: tumor-mediated induction of myeloid-derived suppressor cells and M2-polarized macrophages by altering intracellular PGE2 catabolism in myeloid cells. J Leukoc Biol. (2010) 88:839-48. doi: 10.1189/jlb. 1209821

55. Wang YC, Hu XB, He F, Feng F, Wang L, Li W, Zhang P, Li D, Jia ZS, Liang $\mathrm{YM}$, et al. Lipopolysaccharide-induced maturation of bone marrow-derived dendritic cells is regulated by Notch signaling through the up-regulation of CXCR4. J Biol Chem. (2009) 284:15993-6003. doi: 10.1074/jbc.M901 144200

56. Wang YC, He F, Feng F, Liu XW, Dong GY, Qin HY, et al. Notch signaling determines the M1 versus M2 polarization of macrophages in antitumor immune responses. Cancer Res. (2010) 70:4840-9. doi: 10.1158/0008-5472.CAN-10-0269

57. Wang SH, Lu QY, Guo YH, Song YY, Liu PJ, Wang YC. The blockage of Notch signalling promoted the generation of polymorphonuclear myeloidderived suppressor cells with lower immunosuppression. Eur J Cancer (2016) 68:90-105. doi: 10.1016/j.ejca.2016.08.019

58. Capietto A-H, Kim S, Sanford DE, Linehan DC, Hikida M, Kumosaki T, et al. Down-regulation of PLC $\gamma 2-\beta$-catenin pathway promotes activation and expansion of myeloid-derived suppressor cells in cancer. J Exp Med. (2013) 210:2257-71. doi: 10.1084/jem.20130281

59. D'Amico L, Mahajan S, Capietto A-H, Yang Z, Zamani A, Ricci B, et al. Dickkopf-related protein 1 (Dkk1) regulates the accumulation and function of myeloid derived suppressor cells in cancer. J Exp Med. (2016) 213:827-40. doi: 10.1084/jem.20150950

60. Kagey $\mathrm{MH}, \mathrm{He} \mathrm{X}$. Rationale for targeting the Wnt signalling modulator Dickkopf-1 for oncology. Br J Pharmacol. (2017) 174:4637-50. doi: 10.1111/bph.13894

61. Knöfler M, Pollheimer J. Human placental trophoblast invasion and differentiation : a particular focus on Wnt signaling. Front Genet. (2013) 4:1-14. doi: 10.3389/fgene. 2013.00190

62. Goyal R, Reinhardt R, Jeltsch A. Accuracy of DNA methylation pattern preservation by the Dnmt1 methyltransferase. Nucleic Acids Res. (2006) 34:1182-8. doi: 10.1093/nar/gkl002

63. Jackson AR, Hegde VL, Nagarkatti PS, Nagarkatti M. Characterization of endocannabinoid-mediated induction of myeloid- derived suppressor cells involving mast cells and MCP-1. J Leukoc Biol. (2014) 95:609-19. doi: $10.1189 /$ jlb.0613350
64. Sido JM, Yang X, Nagarkatti PS, Nagarkatti M. $\Delta 9$-Tetrahydrocannabinolmediated epigenetic modifications elicit myeloid- derived suppressor cell activation via STAT3 / S100A8. J Leukocyte Biol. (2015) 97:677-88. doi: 10.1189/jlb.1A1014-479R

65. Fischle W, Wang Y, Allis CD. Histone and chromatin cross-talk. Curr Opin Cell Biol. (2003) 15:172-83. doi: 10.1016/S0955-0674(03)00013-9

66. Rosborough BR, Castellaneta A, Natarajan S, Thomson AW. Histone deacetylase inhibition facilitates GM-CSF-mediated expansion of myeloid-derived suppressor cells in vitro and in vivo. (2012) 91:701-9. doi: 10.1189/jlb.0311119

67. Sahakian E, Powers JJ, Chen J, Deng SL, Cheng F, Distler A. Histone deacetylase 11 : a novel epigenetic regulator of myeloid derived suppressor cell expansion and function. Mol Immunol. (2016) 63:579-85. doi: 10.1016/j.molimm.2014.08.002

68. Youn J, Kumar V, Collazo M, Nefedova Y, Condamine T, Cheng P. Epigenetic silencing of retinoblastoma gene regulates pathologic differentiation of myeloid cells in cancer. Nat Immunol. (2013) 14:211-20. doi: 10.1038/ni.2526

69. Xin J, Zhang Z, Su X, Wang L, Zhang Y, Yang R, et al. Epigenetic component p66a modulates myeloid-derived suppressor cells by modifying STAT3. J Immunol. (2018) 198:2712-20. doi: 10.4049/jimmunol. 1601712

70. Noman MZ, Janji B, Hu S, Wu JC, Martelli F, Bronte V, et al. TumorPromoting Effects of Myeloid-Derived Suppressor Cells Are Potentiated by Hypoxia-Induced Expression of miR-210. Cancer Res. (2015) 75:3771-87. doi: 10.1158/0008-5472.CAN-15-0405

71. Tian J, Rui K, Tang X, Ma J, Wang Y, Tian X, et al. MicroRNA-9 regulates the Di erentiation and function of myeloid- derived suppressor cells via targeting Runx1. J Immunol. (2015) 1:1301-11. doi: 10.4049/jimmunol. 1500209

72. Liu Y, Lai L, Chen Q, Song Y, Xu S, Wang X, et al. MicroRNA-494 is required for the accumulation and functions of tumor-expanded myeloid-derived suppressor cells via targeting of PTEN. J Immunol. (2012) 188:5500-10. doi: 10.4049/jimmunol.1103505

73. Hegde VL, Tomar S, Jackson A, Rao R, Yang X, Singh UP, et al. Distinct microRNA expression pro le and targeted biological pathways in functional myeloid-derived suppressor cells induced by $\Delta 9$-tetrahydrocannabinol in vivo $\alpha$ by microRNA-690 *. BMC Genomics (2017) 18:660. doi: 10.1186/ s12864-017-4070-2

74. Cells MS. MicroRNA-155 and microRNA-21 promote the expansion of functional. J Immunol. (2014) 192:1034-43. doi: 10.4049/jimmunol.1301309

75. Zhang M, Liu Q, Mi S, Liang X, Zhang Z, Su X, et al. Both miR-17-5p and miR-20a alleviate suppressive potential of myeloid-derived suppressor cells by modulating STAT3 expression. J Immunol. (2011) 186:4716-24. doi: 10.4049/jimmunol.1002989

76. Garzon R, Pichiorri F, Palumbo T, Visentini M, Aqeilan R, Cimmino A, et al. MicroRNA gene expression during retinoic acid- induced differentiation of human acute promyelocytic leukemia. Oncogene (2007) 26:41485.doi: 10.1038/sj.onc.1210186

77. Chen S, Huang A, Chen H, Yang Y, Xia F, Jin L, et al. miR-34a inhibits the apoptosis of MDSCs by suppressing the expression of N-myc. Immunol Cell Biol. (2016) 94:563-72. doi: 10.1038/icb.2016.11

78. Liu Q, Zhang M, Jiang X, Zhang Z, Dai L, Min S, et al. miR-223 suppresses differentiation of tumor-induced. Int J Cancer (2011) 2673:266273. doi: $10.1002 / \mathrm{ijc} .25921$

79. Rosa A, Ballarino M, Sorrentino A, Sthandier O, Angelis FG De, Marchioni $\mathrm{M}$, et al. The interplay between the master transcription factor PU . 1 and miR-424 regulates human monocyte / macrophage differentiation. Proc Natl Acad Sci USA. (2007) 104:19849-54. doi: 10.1073/pnas.07069 63104

80. Boldin MP, Taganov KD, Rao DS, Yang L, Zhao JL, Kalwani M. miR-146a is a significant brake on autoimmunity, myeloproliferation, and cancer in mice. J Exp Med. (2011) 208:1189-201. doi: 10.1084/jem.20101823t

81. Shao B, Wei X, Luo M, Yu J, Tong A, Ma X, et al. Inhibition of A20 expression in tumor microenvironment exerts anti-tumor effect through inducing myeloid-derived suppressor cells apoptosis. Sci Rep. (2015) 5:16437. doi: 10.1038/srep16437

82. Zhang Q, Hossain DS, Nechaev S, Kozlowska A, Zhang W, Liu Y. TLR9-mediated siRNA delivery for targeting of normal and malignant 
human hematopoietic cells in vivo. Blood (2013) 121:1304-15. doi: 10.1182/blood-2012-07-442590

83. Hossain DMS, Pal SK, Moreira D, Duttagupta P, Zhang Q. TLR9-targeted STAT3 silencing abrogates immunosuppressive activity of myeloid-derived suppressor cells from prostate cancer patients. Clin Cancer Res. (2016) 21:3771-82. doi: 10.1158/1078-0432.CCR-14-3145

84. Pan P, Wang GX, Yin B, Ozao J, Ku T, Divino CM, et al. Reversion of immune tolerance in advanced malignancy : modulation of myeloid-derived suppressor cell development by blockade of stem-cell factor function. Blood (2008) 111:219-28.doi: 10.1182/blood-2007-04-086835

85. Cheng P, Kumar V, Liu H, Youn J, Fishman M, Sherman S. Effects of Notch signaling on regulation of myeloid cell differentiation in cancer. (2015) Cancer Res. 74:141-52. doi: 10.1158/0008-5472.CAN-13-1686

86. Qiao Y, Pan Y, Ling W, Tian F, Chen Y, Zhang X, et al. The Yin and Yang of regulatory $\mathrm{T}$ cell and therapy progress in autoimmune disease. Autoimmun Rev. (2017) 16:1058-70. doi: 10.1016/j.autrev.2017.08.001

87. Ben-Meir K, Twaik N, Baniyash M. Plasticity and biological diversity of myeloid derived suppressor cells. Curr Opin Immunol. (2018) 51:154-61. doi: 10.1016/j.coi.2018.03.015

88. Zhang W, Li J, Qi G, Tu G, Yang C, Xu M. Myeloid-derived suppressor cells in transplantation: the dawn of cell therapy. J Transl Med. (2018) 16:19. doi: 10.1186/s12967-018-1395-9

89. Wang T, Wen Y, Fan X. Myeloid-derived suppressor cells suppress CD4 + $\mathrm{T}$ cell activity and prevent the development of type 2 diabetes. Acta Biochim Biophys Sin. (2018) 50:362-9. doi: 10.1093/abbs/gmy014

90. Choi W, Ji YW, Ham HY, Yeo A, Noh H, Jin SE, et al. Gr $-1^{\text {int }} \mathrm{CD} 11 b^{+}$ myeloid-derived suppressor cells accumulate in corneal allograft and improve corneal allograft survival. J Leukoc Biol. (2016) 100:1453-63. doi: 10.1189/jlb.5A1115-508RR

91. Köstlin N, Kugel H, Spring B, Leiber A, Marmé A, Henes M, et al. Granulocytic myeloid derived suppressor cells expand in human pregnancy and modulate T-cell responses. Eur J Immunol. (2014) 44:2582-91. doi: $10.1002 /$ eji.201344200

92. De Sanctis F, Bronte V, Ugel S. Tumor-induced myeloidderived suppressor cells. Microbiol Spectr. (2016) 4. doi: 10.1128/microbiolspec.MCHD-0016-2015

93. Nair RR, Sinha P, Khanna A, Singh K. Reduced myeloid-derived suppressor cells in the blood and endometrium is associated with early miscarriage. Am J Reprod Immunol. (2015) 73:479-86. doi: 10.1111/aji.12351

94. Papatriantafyllou M. Tumour immunology: MDSCs come at a cost. Nat Rev Immunol. (2011) 11:440. doi: 10.1038/nri3017

95. Veglia F, Perego M, Gabrilovich D. Myeloid-derived suppressor cells coming of age. Nat Immunol. (2018) 19:108-19. doi: 10.1038/s41590-017-0022-x

96. Zhu M, Huang X, Yi S, Sun H, Zhou J. High granulocytic myeloidderived suppressor cell levels in the peripheral blood predict a better IVF treatment outcome. J Matern Neonatal Med. (2017) 27:1-6. doi: 10.1080/14767058.2017.1400002

97. Wang Y, Liu Y, Shu C, Wan J, Shan Y, Zhi X, et al. Inhibition of pregnancyassociated granulocytic myeloid-derived suppressor cell expansion and arginase-1 production in preeclampsia. J Reprod Immunol. (2018) 127:48-54. doi: $10.1016 /$ j.jri.2018.05.002

98. Zhang T, Zhou J, Chi G, Man W, Leung KT, Liang B, et al. MDSCs drive the process of endometriosis by enhancing angiogenesis and are a new potential therapeutic target. Eur I Immunol. 48:1059-73. doi: 10.1002/eji.201747417

99. Schwarz J, Scheckenbach V, Kugel H, Spring B, Pagel J, Härtel C, et al. Granulocytic myeloid-derived suppressor cells (GR-MDSC) accumulate in cord blood of preterm infants and remain elevated during the neonatal period. Clin Exp Immunol. (2018) 191:328-37. doi: 10.1111/cei.13059

100. He Y, Li X, Perego M, Nefedova Y, Kossenkov AV, Jensen EA, et al. Transitory presence of myeloid-derived suppressor cells in neonates is critical for control of inflammation. Nat Med. (2018) 24:224-31. doi: 10.1038/nm. 4467

101. Diaz-Montero CM, Salem ML, Nishimura MI, Garrett-Mayer E, Cole DJ, Montero AJ. Increased circulating myeloid-derived suppressor cells correlate with clinical cancer stage, metastatic tumor burden, and doxorubicincyclophosphamide chemotherapy. Cancer Immunol Immunother. (2009) 58:49-59. doi: 10.1007/s00262-008-0523-4
102. Nagaraj S, Schrum AG, Cho H-I, Celis E, Gabrilovich DI. Mechanism of $\mathrm{T}$ cell tolerance induced by myeloid-derived suppressor cells. J Immunol. (2010) 184:3106-16. doi: 10.4049/jimmunol.0902661

103. Gros A, Turcotte S, Wunderlich JR, Ahmadzadeh M, Dudley ME, Rosenberg SA. Myeloid cells obtained from the blood but not from the tumor can suppress T-cell proliferation in patients with melanoma. Clin Cancer Res. (2012) 18:5212-23. doi: 10.1158/1078-0432.CCR-12-1108

104. Gabrilovich DI, Nagaraj S. Myeloid-derived suppressor cells as regulators of the immune system. Nat Rev Immunol. (2009) 9:162. doi: 10.1038/nri2506

105. Sun HL, Zhou X, Xue YF, Wang K, Shen YF, Mao JJ, et al. Increased frequency and clinical significance of myeloid-derived suppressor cells in human colorectal carcinoma. World J Gastroenterol. (2012) 18:3303. doi: 10.3748/wjg.v18.i25.3303

106. Wesolowski R, Markowitz J, Paul B, Carothers S, Abdel-Rasoul M, Carson WE. Study of circulating myeloid derived suppressor cells (MDSC) in patients with breast cancer undergoing neo-adjuvant chemotherapy; interim results. J Immunother Cancer (2013) 1:P66. doi: 10.1186/2051-1426-1-S1-P66

107. Chouaib S. Targeting myeloid-derived suppressor cells to bypass tumor- induced immunosuppression. Front Immunol. (2018) 9:398. doi: 10.3389/fimmu.2018.00398

108. Tang C-HA, Chang S, Hashimoto A, Chen YJ, Kang CW, Mato $\mathrm{AR}$, et al. Secretory IgM exacerbates tumor progression by inducing accumulations of MDSCs in mice. Cancer Immunol Res. (2018) 6:696-710. doi: 10.1158/2326-6066.CIR-17-0582

109. Elliott LA, Doherty GA, Sheahan K, Ryan EJ. Human Tumor-infiltrating Myeloid Cells : Phenotypic and Functional Diversity. (2017) Front Immunol. 8:86. doi: 10.3389/fimmu. 2017.00086

110. Gabitass RF, Annels NE, Stocken DD, Pandha HA, Middleton GW. Elevated myeloid-derived suppressor cells in pancreatic, esophageal and gastric cancer are an independent prognostic factor and are associated with significant elevation of the Th2 cytokine interleukin-13. Cancer Immunol Immunother. (2011) 60:1419-30. doi: 10.1007/s00262-011-1028-0

111. Eruslanov E, Neuberger M, Daurkin I, Perrin GQ, Algood C, Dahm P, et al. Circulating and tumor-infiltrating myeloid cell subsets in patients with bladder cancer. Int J Cancer (2012) 130:1109-19. doi: 10.1002/ijc.26123

112. Jiang H, Gebhardt C, Umansky L, Beckhove P, Schulze TJ, Utikal J, et al. Elevated chronic inflammatory factors and myeloid-derived suppressor cells indicate poor prognosis in advanced melanoma patients. Int J Cancer (2015) 136:2352-60. doi: $10.1002 /$ ijc. 29297

113. Khaled YS, Ammori BJ, Elkord E. Myeloid-derived suppressor cells in cancer: recent progress and prospects. Immunol Cell Biol. (2013) 91:493-502. doi: $10.1038 / \mathrm{icb} .2013 .29$

114. Wesolowski R, Markowitz J, Carson WE. Myeloid derived suppressor cellsa new therapeutic target in the treatment of cancer. J Immunother Cancer (2013) 1:10. doi: 10.1186/2051-1426-1-10

115. Fleming V, Umansky V. Two MDSC faces in obesity: correcting metabolic dysfunctions but promoting tumor development. J Leukoc Biol. (2018) 103:373-5. doi: 10.1002/JLB.3CE1017-416R

116. Gao Y, Wang T, Li Y, Zhang Y, Yang R. Lnc-chop promotes immunosuppressive function of myeloid-derived suppressor cells in tumor and inflammatory environments. J Immunol. (2018) 200:2603-14. doi: 10.4049/jimmunol.1701721

117. Tavazoie MF, Pollack I, Tanqueco R, Ribas A, Mucida D, Tavazoie SF, et al. Article LXR/ApoE activation restricts innate immune suppression in cancer article LXR/ApoE activation restricts innate immune suppression in cancer. Cell (2018) 172:825-40.e18. doi: 10.1016/j.cell.2017.12.026

118. Waldron TJ, Quatromoni JG, Karakasheva TA, Singhal S, Rustgi AK. Myeloid derived suppressor cells: targets for therapy. Oncoimmunology (2013) 2:e24117. doi: 10.4161/onci.24117

119. Karakasheva TA, Dominguez GA, Hashimoto A, Lin EW, Chiu C, Sasser K, et al. CD38+ M-MDSC expansion characterizes a subset of advanced colorectal cancer patients. JCI Insight (2018) 3:97022. doi: 10.1172/jci.insight. 97022

120. Weber R, Fleming V, Hu X, Nagibin V, Groth C, Altevogt P, et al. Myeloid-derived suppressor cells hinder the anti-cancer activity of immune checkpoint inhibitors. Front Immunol. (2018) 9:1310. doi: 10.3389/fimmu.2018.01310. 
121. Marin-Acevedo JA, Soyano AE, Dholaria B, Knutson KL, Lou Y. Cancer immunotherapy beyond immune checkpoint inhibitors. J Hematol Oncol. (2018) 11:8. doi: 10.1186/s13045-018-0582-8

122. Guzhova I V, Margulis BA. HSP70-based anti-cancer immunotherapy. Hum Vaccin Immunother. (2016) 12:2529-35. doi: 10.1080/21645515.2016.1190057

123. Scalapino KJ, Daikh DI. CTLA-4: a key regulatory point in the control of autoimmune disease. Immunol Rev. (2008) 223:143-55. doi: 10.1111/j.1600-065X.2008.00639.x

124. Lühder F, Höglund P, Allison JP, Benoist C, Mathis D. Cytotoxic $\mathrm{T}$ lymphocyte-associated antigen 4 (CTLA-4) regulates the unfolding of autoimmune diabetes. J Exp Med. (1998) 187:427-32. doi: 10.1084/jem.187.3.427

125. Karandikar NJ, Vanderlugt CL, Walunas TL, Miller SD, Bluestone JA. CTLA4: a negative regulator of autoimmune disease. J Exp Med. (1996) 184:783-8. doi: $10.1084 /$ jem.184.2.783

126. Baniyash M. Myeloid-derived suppressor cells as intruders and targets: clinical implications in cancer therapy. Cancer Immunol Immunother. (2016) 65:857-67. doi: 10.1007/s00262-016-1849-y

127. Sharma P, Hu-Lieskovan S, Wargo JA, Ribas A. Primary, adaptive, and acquired resistance to cancer immunotherapy. Cell (2017) 168:707-23. doi: 10.1016/j.cell.2017.01.017

128. Orillion A, Hashimoto A, Damayanti NP, Shen L, Adelaiye-Ogala R, Arisa S, et al. Entinostat neutralizes myeloid derived suppressor cells and enhances the antitumor effect of PD-1 inhibition in murine models of lung and renal cell carcinoma. Clin Cancer Res. (2017) 23:5187-201. doi: 10.1158/1078-0432.CCR-17-0741

129. Boros P, Ochando J, Zeher M. Myeloid derived suppressor cells and autoimmunity. Hum Immunol. (2016) 77:631-6. doi: 10.1016/j.humimm.2016.05.024

130. Sica A, Massarotti M. Myeloid suppressor cells in cancer and autoimmunity. J Autoimmun. (2017) 85:117-25. doi: 10.1016/j.jaut.2017.07.010

131. Elliott DM, Singh N, Nagarkatti M, Nagarkatti P. cannabidiol attenuates experimental autoimmune encephalomyelitis model of multiple sclerosis through induction of myeloid-derived suppressor cells. Front Immunol. (2018) 9:1782. doi: 10.3389/fimmu.2018.01782

132. van der Touw W, Kang K, Luan Y, Ma G, Mai S, Qin L, et al. Glatiramer acetate enhances myeloid-derived suppressor cell function via recognition of paired Ig-like receptor B. J Immunol. (2018) 201:1727-34. doi: 10.4049/jimmunol.1701450.

133. Guo C, Hu F, Yi H, Feng Z, Li C, Shi L, et al. Myeloid-derived suppressor cells have a proinflammatory role in the pathogenesis of autoimmune arthritis. Ann Rheum Dis. (2014) 75:278-85. doi: 10.1136/annrheumdis-2014-205508

134. Zhang H, Wang S, Huang Y, Wang H, Zhao J, Gaskin F, et al. Myeloidderived suppressor cells are proinflammatory and regulate collagen-induced arthritis through manipulating Th17 cell differentiation. Clin Immunol. (2015) 157:175-86. doi: 10.1016/j.clim.2015.02.001

135. Bueno V, Sant'Anna OA, Lord JM. Ageing and myeloid-derived suppressor cells: possible involvement in immunosenescence and age-related disease. Age (2014) 36:9729. doi: 10.1007/s11357-014-9729-x

136. Flores RR, Clauson CL, Cho J, Lee B, Mcgowan SJ, Baker DJ, Niedernhofer LJ, Robbins PD. Expansion of myeloid-derived suppressor cells with aging in the bone marrow of mice through a NF-кB-dependent mechanism. Aging Cell (2017) 16:480-7. doi: 10.1111/acel.12571

137. Okwan-Duodu D, Umpierrez GE, Brawley OW, Diaz R. Obesity-driven inflammation and cancer risk: role of myeloid derived suppressor cells and alternately activated macrophages. Am J Cancer Res. (2013) 3:21.

138. Hale M, Itani F, Buchta CM, Wald G, Bing M, et al. Obesity triggers enhanced MDSC accumulation in murine renal tumors via elevated local production of CCL2. PLoS ONE (2015) 10:e0118784. doi: 10.1371/journal.pone.01 18784

139. Chen S, Akbar SMF, Miyake T, Abe M, Al-Mahtab M, Furukawa S, et al. Diminished immune response to vaccinations in obesity: Role of myeloidderived suppressor and other myeloid cells. Obes Res Clin Pract. (2015) 9:35-44. doi: 10.1016/j.orcp.2013.12.006

140. Ostrand-Rosenberg S. Myeloid derived-suppressor cells: their role in cancer and obesity. Curr Opin Immunol. (2018) 51:68-75. doi: 10.1016/j.coi.2018.03.007
141. Nakamura T, Ushigome H. Myeloid-Derived suppressor cells as a regulator of immunity in organ transplantation. Int J Mol Sci. (2018) 19:2357. doi: 10.3390/ijms19082357

142. Ochando JC, Chen SH. Myeloid-derived suppressor cells in transplantation and cancer. Immunol Res. (2012) 54:275-85. doi: 10.1007/s12026-012-8335-1

143. Dugast AS, Haudebourg T, Coulon F, Heslan M, Haspot F, Poirier N, et al. Myeloid-derived suppressor cells accumulate in kidney allograft tolerance and specifically suppress effector $\mathrm{T}$ cell expansion. J Immunol. (2008) 180:7898-906. doi: 10.4049/jimmunol.180.12.7898

144. Zhang C, Wang S, Yang C, Rong R. The crosstalk between myeloid derived suppressor cells and immune cells: to establish immune tolerance in transplantation. J Immunol Res (2016) 2016:4986797. doi: $10.1155 / 2016 / 4986797$

145. Wu T, Zhao Y, Zhao Y. The roles of myeloid-derived suppressor cells in transplantation. Expert Rev Clin Immunol. (2014) 10:1385-94. doi: 10.1586/1744666X.2014.948424

146. Okano S, Abu-Elmagd K, Kish DD, Keslar K, Baldwin III WM, et al. Myeloid-derived suppressor cells increase and inhibit donor-reactive $\mathrm{T}$ cell responses to graft intestinal epithelium in intestinal transplant patients. Am J Transplant. (2018) 18:2544-58. doi: 10.1111/ajt.14718

147. Du XX, Guo YL, Zhao YP, Yang M, Chang S, Liu B, Cai LJ, Chen ZK. Accumulation of high levels of monocytic myeloid-derived suppressor cells enhances graft survival in almost tolerant kidney transplant recipients. Transplant Proc. (in press) doi: 10.1016/j.transproceed.2018. 04.043

148. Guan W, Ding Y, Liu B, Du J. Dexamethasone-induced myeloid-derived suppressor cells prolong allo cardiac graft survival through inOs- and glucocorticoid receptor-Dependent Mechanism. Front Immunol. (2018) 9:282. doi: 10.3389/fimmu.2018.00282

149. Yang F, Li Y, Zhang Q, Tan L, Peng L, Zhao Y. The Effect of immunosuppressive drugs on MDSCs in transplantation. J Immunol Res. (2018) 2018:5414808. doi: 10.1155/2018/5414808

150. Dorhoi A, Plessis ND. Monocytic myeloid-derived suppressor cells in chronic infections. Front Immunol. (2018) 8:1895. doi: 10.3389/fimmu.2017.01895

151. Wang C, Zhang N, Qi L, Yuan J, Wang K, Ma S, et al. Myeloidderived suppressor cells inhibit $\mathrm{t}$ follicular helper cell immune response in Japanese encephalitis virus infection. J Immunol. (2017) 199:3094-105. doi: 10.4049/jimmunol.1700671

152. Janols H, Bergenfelz C, Allaoui R, Larsson AM, Rydén L, Björnsson S, et al. High frequency of myeloid-derived suppressor cells in sepsis patients, with the granulocytic subtype dominating in Gram-positive cases. Crit Care (2014) 18:1-53. doi: 10.1186/cc14006

153. Cuenca AG, Moldawer LL. Myeloid-derived suppressor cells in sepsis: friend or foe? Intensive Care Med. (2012) 38:928-30. doi: 10.1007/s00134-012-2575-3

154. Kolahian S, Öz HH, Zhou B, Griessinger CM, Rieber N, Hartl D. The emerging role of myeloid-derived suppressor cells in lung diseases. Eur Respir J. (2016) 47:967-77. doi: 10.1183/13993003.01572-2015

155. Zhang H, Lian M, Zhang J, Bian Z, Tang R, Miao Q, et al. A functional characteristic of cysteine-rich protein 61: modulation of myeloid-derived suppressor cells in liver inflammation. Hepatology (2018) 67:232-46. doi: $10.1002 /$ hep. 29418

156. Heim CE, Vidlak D, Odvody J, Hartman CW, Garvin KL, Kielian T. Human prosthetic joint infections are associated with myeloid-derived suppressor cells (MDSCs): implications for infection persistence. J Orthop Res. (2018) 36:1605-13. doi: 10.1002/jor.23806

157. Poe SL, Arora M, Oriss TB, Yarlagadda M, Isse K, Khare A, et al. STAT1regulated lung MDSC-like cells produce IL-10 and efferocytose apoptotic neutrophils with relevance in resolution of bacterial pneumonia. Mucosal Immunol. (2013) 6:189. doi: 10.1038/mi.2012.62

158. Sander LE, Sackett SD, Dierssen U, Beraza N, Linke RP, Müller M, et al. Hepatic acute-phase proteins control innate immune responses during infection by promoting myeloid-derived suppressor cell function. J Exp Med. (2010) 207:1453-64. doi: 10.1084/jem.20091474

159. Derive M, Bouazza Y, Alauzet C, Gibot S. Myeloid-derived suppressor cells control microbial sepsis. Intensive Care Med. (2012) 38:1040-9. doi: $10.1007 /$ s00134-012-2574-4 
160. McPeak MB, Youssef D, Williams DA, Pritchett C, Yao ZQ, McCall CE, et al. Myeloid-specific knockout of NFI-A improves sepsis survival. Infect Immun (2017) 85:e00066-17. doi: 10.1128/IAI.00066-17

161. McPeak MB, Youssef D, Williams DA, Pritchett CL, Yao ZQ, McCall CE, et al. Frontline Science: Myeloid cell-specific deletion of Cebpb decreases sepsisinduced immunosuppression in mice. J Leukoc Biol. (2017) 102:191-200. doi: 10.1189/jlb.4HI1216-537R

162. Martire-Greco D, Rodriguez-Rodrigues N, Castillo LA, Vecchione MB, de Campos-Nebel M, Moreno MC, et al. Novel use of all-transretinoic acid in A model of lipopolysaccharide-immunosuppression to decrease the generation of myeloid-derived suppressor cells by reducing the proliferation of CD34+ precursor cells. Shock (2017) 48:94-103. doi: 10.1097/SHK.0000000000000812

163. Salminen A, Kaarniranta K, Kauppinen A. The potential importance of myeloid-derived suppressor cells (MDSCs) in the pathogenesis of Alzheimer's disease. Cell Mol Life Sci. (2018) 75:3099-120. doi: 10.1007/s00018-018-2844-6

164. Vaknin I, Kunis G, Miller O, Butovsky O, Bukshpan S, Beers DR, et al. Excess circulating alternatively activated myeloid (M2) cells accelerate ALS progression while inhibiting experimental autoimmune encephalomyelitis. PLoS ONE (2011) 6:e26921. doi: 10.1371/journal.pone.0026921
165. Chen S, Liu Y, Niu Y, Xu Y, Zhou Q, Xu X, et al. Increased abundance of myeloid-derived suppressor cells and Th17 cells in peripheral blood of newly-diagnosed Parkinson's disease patients. Neurosci Lett. (2017) 648:21-5. doi: 10.1016/j.neulet.2017. 03.045

166. Zhou L, Miao K, Yin B, Li H, Fan J, Zhu Y, et al. Cardioprotective role of myeloid-derived suppressor cells in heart failure. Circulation (2018) 138:181-97. doi: 10.1161/CIRCULATIONAHA.117.03 0811

Conflict of Interest Statement: The authors declare that the research was conducted in the absence of any commercial or financial relationships that could be construed as a potential conflict of interest.

Copyright $\odot 2018$ Budhwar, Verma, Verma, Rai and Singh. This is an open-access article distributed under the terms of the Creative Commons Attribution License (CC $B Y)$. The use, distribution or reproduction in other forums is permitted, provided the original author(s) and the copyright owner(s) are credited and that the original publication in this journal is cited, in accordance with accepted academic practice. No use, distribution or reproduction is permitted which does not comply with these terms. 